\title{
Buckling Temperature and Natural Frequencies of Thick Porous Functionally Graded Beams Resting on Elastic Foundation in a Thermal Environment
}

\author{
Zakaria Ibnorachid $\left(\mathbb{D},{ }^{1}\right.$ Lhoucine Boutahar, ${ }^{1}$ Khalid EL Bikri, ${ }^{1}$ and Rhali Benamar ${ }^{2}$ \\ ${ }^{1}$ Mohammed V University in Rabat, ENSET-Rabat, M2SM, B.P. 6207, Rabat Instituts, Rabat, Morocco \\ ${ }^{2}$ Mohammed V University in Rabat, LERSIM, Rabat, B.P. 765, Agdal, Rabat, Morocco
}

Correspondence should be addressed to Zakaria Ibnorachid; ibnorachid@gmail.com

Received 21 April 2019; Accepted 26 June 2019; Published 4 December 2019

Academic Editor: Mohammad Tawfik

Copyright (c) 2019 Zakaria Ibnorachid et al. This is an open access article distributed under the Creative Commons Attribution License, which permits unrestricted use, distribution, and reproduction in any medium, provided the original work is properly cited.

In this paper, free vibrations of Porous Functionally Graded Beams (P-FGBs), resting on two-parameter elastic foundations, and exposed to three forms of thermal field, uniform, linear, and sinusoidal, are studied using a Refined Higher-order shear Deformation Theory. The present theory accounts for shear deformation by considering a constant transverse displacement and a higher-order variation of the axial displacement through the thickness of the beam. The stress-free boundary conditions are satisfied on the upper and lower surfaces of the beam without using any shear correction factor. The material properties are temperature-dependent and vary continuously through the depth direction of the beam, based on a modified power-law rule, in which two kinds of porosity distributions, uniform, and nonuniform, through the cross-section area of the beam, are considered. Hamilton's principle is applied to obtain governing equations of motion, which are solved using a Navier-type analytical solution for simply supported P-FGB. Numerical examples are proposed and discussed in detail, to prove the effect of the thermal environment, the porosity distribution, and the influence of several parameters such as the power-law index, porosity volume fraction, slenderness ratio, and elastic foundation parameters on the critical buckling temperatures and the natural frequencies of the P-FGB.

\section{Introduction}

The use of structural components made of composite materials is broadly used in various engineering applications, especially those subjected to thermo-mechanical loading. In conventional laminated composite structures, homogeneous elastic laminas are bonded together to obtain enhanced mechanical and thermal properties. However, the abrupt change in material properties across the interface between different materials can result in large interlaminar stresses leading to delimitation, cracking, and other damage mechanisms.

To remedy such defects, Functionally Graded Materials (FGMs) have been proposed, because the mixture ratio of their constituents varies smoothly, and the material characteristics continually change along some preferred direction. This largely avoids the stress concentration, induced by the material property discontinuities, typically observed in laminated and fiber-reinforced composites.
The FGMs exhibit many attractive properties. One can mention the multi-functionality, the possibility to control deformation, resistance, dynamic response, to minimize or completely remove stress concentrations, to smooth thermal stress transition and increase resistance to oxidation. Typically, these materials are made from a mixture of ceramics and metal or a combination of different materials. Ceramic provides high-temperature resistance due to its low thermal conductivity and protects metal from oxidation. The metal, a ductile material, on the other hand, prevents fracture caused by the stresses due to high-temperature gradients. In addition, a mixture of a ceramic and a metal with a continuously varying volume fraction can be easily manufactured [1].

The rapid development of composite materials and structures in recent years has drawn increased attention from many engineers and researchers, because of their multiple potential applications, and particularly their growing use in aeronautic and aerospace engineering as heat shields. This includes 
nuclear reactors, rocket nozzles, and heat engine components. Indeed, FGM's are among the advanced high temperature materials capable of withstanding extreme temperature environments. Thus, there is a need to be able to accurately analyze the dynamic behavior of the FGMs in thermal environments. This necessity has led researchers to investigate several structures made of FGM using a considerable amount of new structural theories. Investigations into the dynamic characteristics of FG structures have been an area of intensive research over the last decade (see Refs. [2-18]).

In view of the advantages of FGMs, several investigations dealing with thermal behaviors have been published in the scientific literature. Recently, Trinh et al. [19] presented an analytical method based on the state space approach to study the vibration and buckling behaviors of Functionally Graded (FG) beams with various boundary conditions under mechanical and thermal loads. They used Hamilton's principle to derive the equations of motion taking into account the thermal effect. El-Megharbel [20] introduced a mathematical analysis to study the FG beam under a thermal loading by assuming two cases of heat distribution along the beam depth: Power and exponential distributions. Şimşek [21] investigated the buckling of the two-dimensional FG beams with different boundary conditions. It was assumed that the material properties of the beam vary in both axial and thickness directions according to the power-law form. The material properties of 2D-FG beams are assumed to vary in both axial and thickness directions according to the power-law form, and the critical buckling load of 2D-FG beams based on the Timoshenko beam theory (TBT) is obtained using the Ritz method. Shahsiah et al. [22] studied the thermal buckling of FG beams. The normalized functions proportional to the thermal buckling loads for thin beams made of FGMs are derived when the beam is under a uniform temperature rise and an axial temperature difference. Eltaher et al. [23] investigated the size-dependent static-buckling behavior of FG nanobeams based on the nonlocal continuum model. The Euler-Bernoulli beam theory is used to modelling nano-beam, and the equilibrium equations are derived using the principle of virtual displacement. The finite element method was used to discretize the model and obtain a numerical approximation of equilibrium equations. A size-dependent inhomogeneous beam model, which accounts for the through-length power-law variation of a two-constituent axial FGM was used by Li et al. [24] to analyze the bending, buckling, and vibration of axial FG beams based on nonlocal strain gradient theory. To consider the significance of strain gradient stress field and nonlocal elastic stress field, respectively, a material length scale parameter and a nonlocal parameter are introduced, respectively, in the axial FG beam model. Concentrated and uniformly distributed loads were considered. On the other hand, Davoodinik et al. [25] derived an analysis of the thermal behavior of FG beams. They assumed that the distribution of material properties followed an exponential function, while for a thermal loading, the steady state of heat conduction with exponential and hyperbolic variations through the thickness of FG beam is considered. Different types of boundary conditions, such as clamped, simply supported, and rolled edges are assumed for edge supports. Based on the nonlinear First-order shear deformation Beam Theory (FBT) and the physical neutral surface concept, Ma et al. [26] derived the governing equations for both the static behavior and the dynamic response of a FG beam subjected to a uniform in-plane thermal loading. Giunta et al. [27] investigated the mechanical behavior of threedimensional beams subjected to thermal stresses. The temperature field was obtained by exactly solving Fourier's heat conduction equation. It is considered as an external load within the mechanical analysis. In addition, Mahi et al. [28] studied the free vibration of a FG beam subjected to thermal environment based on a unified higher order shear deformation theory. They utilized an analytical method to obtain the natural frequencies for various boundary conditions. Based on a new third-order shear deformation theory, Thom and Kien [29] investigated the free vibrations of two-directional functionally graded material beams in a thermal environment. The material properties were considered to be temperature-dependent and are assumed to change along both the thickness and longitudinal directions by a power law distribution.

Structures resting on elastic foundations have been widely adopted by many researchers to model the interaction between elastic media and structures for various engineering problems. There exist a number of previous studies on the effect of elastic foundations on the free vibration of beams. Akgoz and Civalek [30] investigated the thermo-mechanical size-dependent buckling behavior of FG micro beams resting on elastic foundations in a thermal environment. A general solution for the free vibration analysis of isotropic beams on variable Winkler elastic foundations was presented by Zhou [31]. An exact method for the vibration analysis of isotropic beams on variable one- and two-parameter elastic foundations was presented by Eisenberger [32]. Sun et al. [33] numerically investigated buckling and post-buckling under thermomechanical deformations of a FG Timoshenko beam resting on a two-parameter nonlinear elastic foundation and subjected to only a temperature rise with the shooting method. Akbas [34] investigated the free vibration and static bending of FG beams resting on Winkler foundations within the Euler Bernoulli beam theory and the Timoshenko beam theory. The material properties of the beam changed in the thickness direction according to power-law distributions. Esfahani et al. [35] studied the thermal buckling and post-buckling of FG Timoshenko beams resting on a nonlinear elastic foundation. Matsunaga [36] analyzed the natural frequencies and buckling stresses of isotropic deep beam-columns resting on a two-parameter elastic foundation, by using the power series expansion method, based on the higher-order shear deformation beam theory. The differential quadrature element method was used by Chen [37], for the free vibration analysis of nonprismatic Bernoulli-Euler beams, resting on Winkler elastic foundations. Malekzadeh and Karami [38] used a mixed differential quadrature and finite element methods to study the free vibration and buckling of isotropic thick beams resting on a twoparameter elastic foundation. Based on the two-dimensional theory of elasticity, exact solutions for the bending, and free vibration of simply supported FG beams resting on a WinklerPasternak elastic foundation were presented by Ying et al. [39]. A differential quadrature element method (DQEM) for the free vibration analysis of arbitrary nonuniform Timoshenko 
beams with attachments, i.e., concentrated mass and rotary inertia, resting on elastic supports was proposed by Karami et al. [40]. Pradhan and Murmu [41] analyzed the thermomechanical vibration of a FG sandwich beam under various elastic foundations by the differential quadrature method. Teifouet et al. [42] examined the buckling of axially functionally graded and nonuniform Timoshenko beams based on the nonlocal TBT. The material properties of 2D-FG beams are assumed to vary in the axial direction and the nanobeam is modelled as a nonuniform Timoshenko beam resting on a Winkler-Pasternak foundation. Rayleigh quotients for the buckling load are derived and the numerical solution is obtained by using Chebyshev polynomials based on the Rayleigh-Ritz method. A unified higher order beam theory, which contains various beam theories, and based on the modified couple stress theory, has been presented by Şimşek and Reddy [43] for the buckling of FG microbeam embedded in elastic Pasternak medium.

With the rapid progression in the technology of structural elements, structures with a graded porosity can be mentioned among the latest developments in FGMs. The microstructure pores are taken into account via a variable local density. Researches have their eyes on the development of manufacturing methods applicable to FGMs such as the powder metallurgy, the vapor deposition, the self-propagation, the centrifugal casting, and the magnetic separation [44-48]. These methods have some disadvantages such as high costs and complexity of the technique. One of the flexible and suitable ways to manufacture FGM is the sintering process. During this process, due to the big difference in solidification between the material constituents, however, the porosities or the micro voids through the material can happen regularly [49]. Much research has been done on porosities occurring inside FGM samples manufactured by a multi-step sequential infiltration technique [50]. According to this work, it is important to take into consideration the porosity effect when designing and analyzing FGM structures. Porous FG structures have many interesting combinations of mechanical properties, such as high stiffness in conjunction with very low specific weight [51]. The studies on the vibration response of porous FG are still limited in number. For porous plates, the nonlinear free vibrations analysis of FG porous annular plates resting on elastic foundations have been presented by Boutahar et al. [52]. They concluded that porosity volume fraction and type of porosity distribution have a significant influence on the geometrically nonlinear free vibration response of the FG annular plates at large amplitudes. Wattanasakulpong and Ungbhakorn [53] investigated linear and nonlinear vibrations of porous Euler FG beams with elastically restrained ends. The material properties of the porous FG beam have been described by a modified rule of mixture. Ebrahimi and Mokhtari [54] provided a differential transformation method for analyzing the vibration of rotating Timoshenko FG beams with porosities. Moreover, Wattanasakulpong and Chaikittiratana [55] predicted the flexural vibrations of porous FG beams using the Timoshenko beam theory. They found that the porosities yield a reduction in the beams' FG mass and strength. Ebrahimi and Zia [56] investigated the large vibration amplitudes of porous FG Timoshenko beams by utilizing the nonlinear
Galerkin and multiple scales methods. Ait Atmane et al. [57] applied an efficient beam theory to study the effects of thickness stretching and porosity on the mechanical responses of FG beams resting on elastic foundations. For beams subjected to thermal environments, the first effort is due to Ebrahimi and Salari [58] who studied the vibration of porous FG Euler beams subjected to thermal loadings. In the above-mentioned study, only one specific porosity distribution was considered and no detailed discussion concerning the effects of different porosity distributions on the thermo-mechanical behavior of porous beams was given. Ebrahimi and Jafari [59] utilized the Timoshenko and Reddy beam theories to investigate the effects of temperature on the vibration of FG beams with two kinds of porosity distributions. In another study [60], the same authors investigated the thermomechanical vibration characteristics of porous FG Reddy beams subjected to various thermal loadings by using a Navier solution method. Zahedinejad [61] studied the free vibration of FG beams with various boundary conditions resting on a two-parameter elastic foundation in the thermal environment by using the third-order shear deformation beam theory. The Differential Quadrature Method (DQM) in conjunction with Hamilton's principle is adopted to discretize the governing equations. In the papers mentioned above, concerned with the thermo-mechanical vibration of FG porous beams utilized the Classic Beam (CBT), the Timoshenko Beam (TBT), and the Reddy Beam Theories (RBT). The CBT ignores the effect of the shear deformation and is not appropriate for thick beams and higher modes of vibration. The first-order shear deformation theory (TBT) overcomes the limitation of the CBT by introducing a shear correction factor in the thickness direction of the beam. However, as it does not lead to the expected zero shear stress on the top and bottom surfaces of the beam, it appeared necessary to develop a Higher order shear Deformation Theory (HDT) which predicts the transverse shear stresses properly without introducing any shear correction factor. By employing the HDT, many researchers investigated the thermo-mechanical behavior of FGM structures. Kadoli et al. [62] investigated the static response of FG beams in a thermal environment using the HDT. Larbi et al. [63], followed by Vo et al. [64] developed, respectively, an efficient shear deformation beam theory and a refined theory for investigating the static and vibrational behavior of FG beams.

This present research focuses on the thermo-mechanical performance of simply supported porous thick FGBs on elastic foundations, subjected to various thermal loadings with two different porosity distributions based on the RHDT. Three types of temperature distributions, through the thickness direction of the beam, are supposed: Uniform (UTR), Linear (LTR), and Sinusoidal (STR) Temperature Rises. The material properties are assumed to be temperature-dependent and graded through the beam thickness according to a modified power-law model. A uniform and a nonuniform porosity distribution, through the thickness direction, are considered. The RHDT is extended to include the influence of several parameters on the linear transverse free vibration of porous FG beams. This theory superimposes the effects of both the bending and shear stresses, and permits a higher-order variation of the axial displacement through the depth of the beam so 


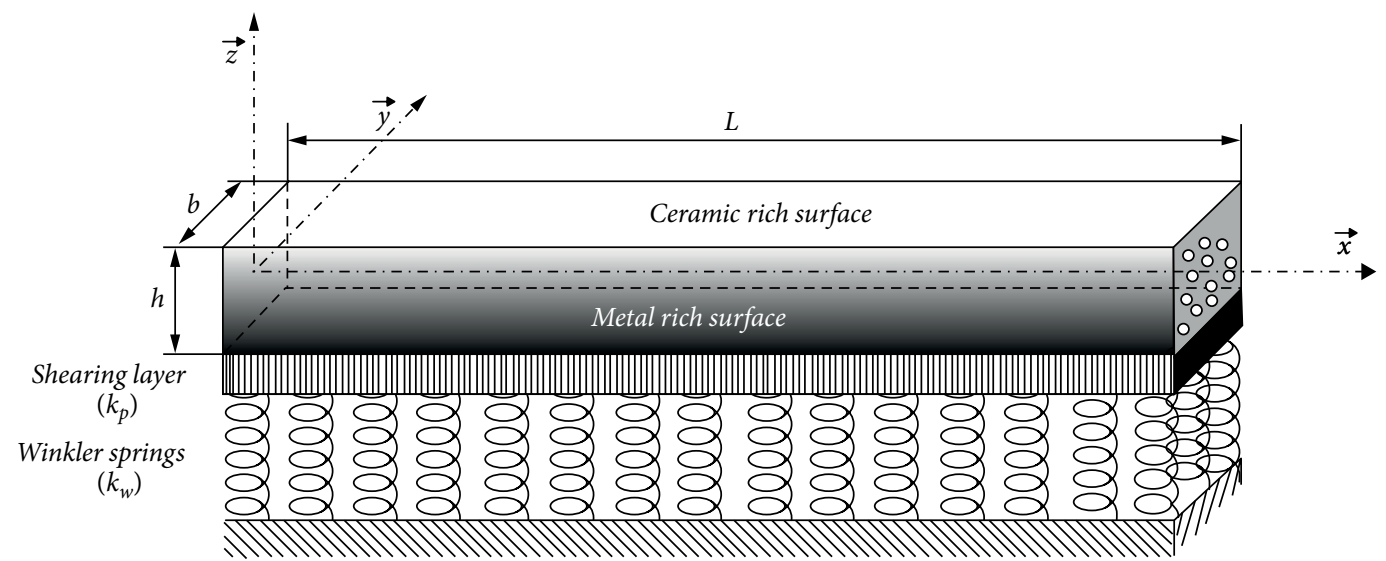

FIGURE 1: Geometry and coordinate system of the P-FGB resting on elastic foundations.

that there is no need for any shear correction factor. The equations of motion of the P-FGB are determined by applying Hamilton's principle and a Navier-type analytical solution.

Several graphical and numerical results are given to illustrate the effects of various specific parameters such as the material index, the porosity volume fraction, the elastic foundation parameters, the porosity distribution, and the thermal environment on the buckling temperatures and natural frequencies of simply supported P-FGBs.

\section{General Formulation}

2.1. Problem Definition. Consider the thick P-FGB shown in Figure 1 having the following characteristics: length $(L)$, rectangular cross section width $(b)$, and height $(h)$. The P-FGB is assumed to rest on a Winkler-Pasternak type elastic foundation with a Winkler stiffness $\left(k_{w}\right)$ and a shear stiffness $\left(k_{p}\right)$.

2.2. Mechanical Properties of P-FGB. The P-FGB examined here is made of a mixture of ceramic and metal, whose compositions vary from the top to the bottom surfaces. The top surface $(z=+h / 2)$ of the beam is ceramic-rich, whereas the bottom surface $(z=-h / 2)$ is metal-rich. The effective material property $P$ (e.g., Young's modulus $E$, mass density $\rho$, thermal expansion coefficient $\alpha$, and Poisson's ratio $\nu$ ) is assumed to vary through the beam thickness as a function of the volume fraction, the properties of the constituent materials and the porosity volume fraction $(\zeta \ll 1)$. For the perfect FGB $\zeta$ is set to zero. As shown in Figure 2, two kinds of porosity distribution, uniform, and nonuniform through the crosssection area of the beam, between the top and bottom surfaces, are considered in this study.

If the porosity distribution is assumed to be uniform, the rule of mixture is modified as follows [52]:

$$
P(z)=P_{m}\left(\vartheta_{m}-\frac{\zeta}{2}\right)+P_{c}\left(\vartheta_{c}-\frac{\zeta}{2}\right),
$$

in which $\vartheta_{c}$ and $\vartheta_{m}$ are the ceramic and metal volume fractions, respectively, related by:

$$
\vartheta_{m}+\vartheta_{c}=1
$$

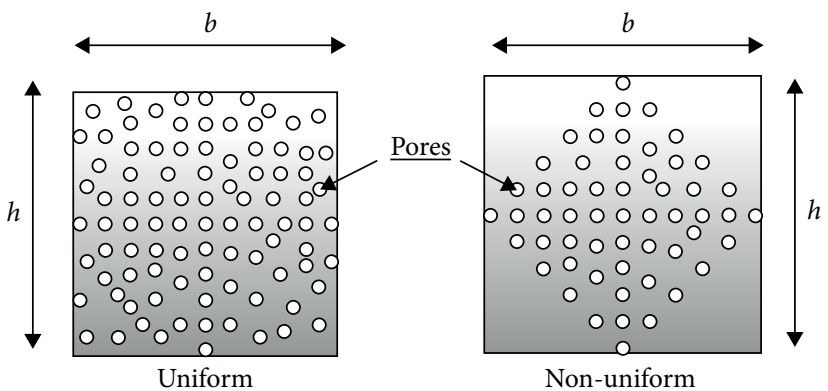

FIGURE 2: Porosity distributions through the cross-section area of P-FGB.

The power law of the ceramic volume $\vartheta_{c}$ is defined by [65]:

$$
\vartheta_{c}(z)=\left(\frac{z}{h}+\frac{1}{2}\right)^{p} ; \quad p \geq 0
$$

$(z)$ is the thickness coordinate measured from the middle surface of the beam $(-h / 2 \leq z \leq+h / 2)$. The power law index ( $p$ ) defines the material variation profile across the beam thickness, and can be varied to get the optimum distribution of the component materials. The variation of the material volume fraction across the FGB thickness associated with the power law distribution is plotted in Figure 3. This figure and Eq. (3) show that if $p$ vanishes the beam reduces to a pure ceramic one. As the gradient index $p$ increases, the ceramic volume fraction decreases until it tends to zero, leading to a pure metal beam.

Hence, all the properties of P-FGB can be written as:

$$
P(z)=\left(P_{c}-P_{m}\right)\left(\frac{z}{h}+\frac{1}{2}\right)^{p}+P_{m}-\frac{\zeta}{2}\left(P_{c}+P_{m}\right) .
$$

For example, Young's modulus, the material density and Poisson's ratio expressions of the P-FGB can be formulated as follows:

$$
\begin{gathered}
E(z)=\left(E_{c}-E_{m}\right)\left(\frac{z}{h}+\frac{1}{2}\right)^{p}+E_{m}-\frac{\zeta}{2}\left(E_{c}+E_{m}\right), \\
\rho(z)=\left(\rho_{c}-\rho_{m}\right)\left(\frac{z}{h}+\frac{1}{2}\right)^{p}+\rho_{m}-\frac{\zeta}{2}\left(\rho_{c}+\rho_{m}\right),
\end{gathered}
$$




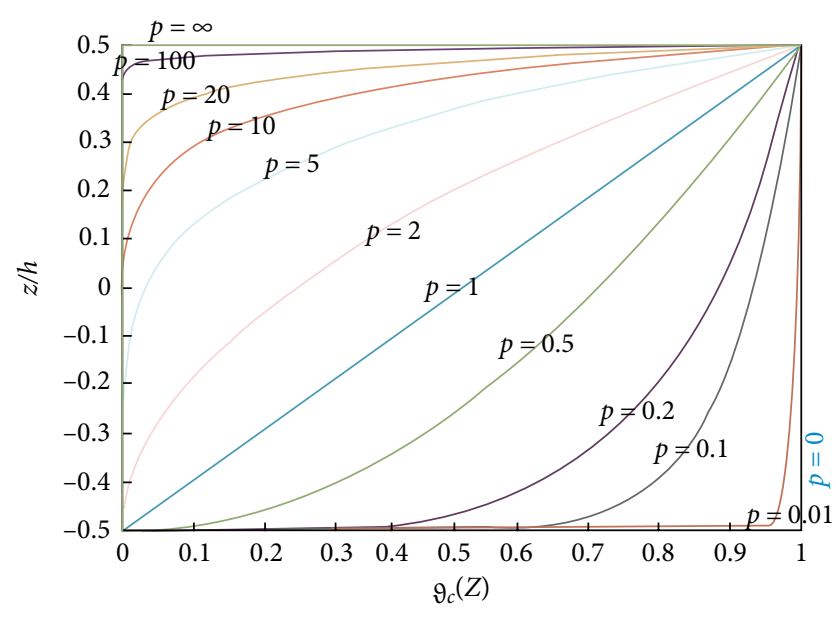

FIGURE 3: Variation of volume fraction $\left(\vartheta_{c}\right)$ across the thickness of FGB for different values of the gradient index $(p)$.

$$
v(z)=\left(v_{c}-v_{m}\right)\left(\frac{z}{h}+\frac{1}{2}\right)^{p}+v_{m}-\frac{\zeta}{2}\left(v_{c}+v_{m}\right) .
$$

In the multi-step sequential infiltration technique used to produce FGM samples, the porosities occur mostly at the beam middle zone [50] in which it is difficult to infiltrate completely the materials, while at the top and bottom zones the process of material infiltration can easily be performed. Therefore, in P-FGB with a nonuniform distribution, the porosities are centralized around the middle zone of the cross-section, and the amount of porosity decreases and tends to zero at the cross-section top and bottom. In this case, the effective material property variations are replaced by the following form [53]:

$$
\begin{aligned}
E(z)= & \left(E_{c}-E_{m}\right)\left(\frac{z}{h}+\frac{1}{2}\right)^{p} \\
& +E_{m}-\frac{\zeta}{2}\left(E_{c}+E_{m}\right)\left(1-\frac{2|z|}{h}\right) \\
\rho(z)= & \left(\rho_{c}-\rho_{m}\right)\left(\frac{z}{h}+\frac{1}{2}\right)^{p} \\
& +\rho_{m}-\frac{\zeta}{2}\left(\rho_{c}+\rho_{m}\right)\left(1-\frac{2|z|}{h}\right) \\
v(z)= & \left(v_{c}-v_{m}\right)\left(\frac{z}{h}+\frac{1}{2}\right)^{p} \\
& +v_{m}-\frac{\zeta}{2}\left(v_{c}+v_{m}\right)\left(1-\frac{2|z|}{h}\right) .
\end{aligned}
$$

2.3. Description of the Thermal Environment. For FGMs working at high temperatures, significant variations in the thermal and mechanical properties of the materials may be expected [66]. For example, the Young's modulus of stainless steel and zirconia are reduced by $37 \%$ and $31 \%$, respectively, when the temperature increases from a room temperature of $300^{\circ} \mathrm{K}$ to $1000^{\circ} \mathrm{K}$ [67]. Therefore, an accurate description of the structure dynamic behavior has to take into account this temperature-dependency. Therefore, the effective Young's modulus $\left(E_{c}\right)$ and $\left(E_{m}\right)$, the material densities $\left(\rho_{c}\right)$ and $\left(\rho_{m}\right)$, and the coefficients of thermal expansion $\left(\alpha_{c}\right)$ and $\left(\alpha_{m}\right)$ are assumed to be temperature-dependent and expressed by nonlinear functions of the temperature [68]:

$$
P(T)=P_{0}\left(P_{-1} T^{-1}+1+P_{1} T+P_{2} T^{2}+P_{3} T^{3}\right),
$$

where $P_{0}, P_{-1}, P_{1}, P_{2}$, and $P_{3}$ are the temperature-dependent coefficients given in Table 1 for $\mathrm{Si}_{3} \mathrm{~N}_{4}$ and SUS304 [69]. The bottom surface $(z=-h / 2)$ of P-FGB is pure metal (SUS304), whereas the top surface $(z=+h / 2)$ is pure ceramic $\left(\mathrm{Si}_{3} \mathrm{~N}_{4}\right)$.

The Young's modulus, the material density, the thermal expansion, and the Poisson's ratio are both temperature and position dependent, and can be expressed in the uniform porosity distribution case as:

$E(z, T)=\left[E_{c}(T)-E_{m}(T)\right]\left(\frac{z}{h}+\frac{1}{2}\right)^{p}+E_{m}(T)-\left[E_{c}(T)+E_{m}(T)\right] \frac{\zeta}{2}$,

$\rho(z, T)=\left[\rho_{c}(T)-\rho_{m}(T)\right]\left(\frac{z}{h}+\frac{1}{2}\right)^{p}+\rho_{m}(T)-\left[\rho_{c}(T)+\rho_{m}(T)\right] \frac{\zeta}{2}$,

$\alpha(z, T)=\left[\alpha_{c}(T)-\alpha_{m}(T)\right]\left(\frac{z}{h}+\frac{1}{2}\right)^{p}+\alpha_{m}(T)-\left[\alpha_{c}(T)+\alpha_{m}(T)\right] \frac{\zeta}{2}$,

$v(z, T)=\left[v_{c}(T)-v_{m}(T)\right]\left(\frac{z}{h}+\frac{1}{2}\right)^{p}+v_{m}(T)-\left[v_{c}(T)+v_{m}(T)\right] \frac{\zeta}{2}$,

and in the nonuniform porosity distribution case as:

$$
\begin{aligned}
E(z, T)= & {\left[E_{c}(T)-E_{m}(T)\right]\left(\frac{z}{h}+\frac{1}{2}\right)^{p} } \\
& +E_{m}(T)-\frac{\zeta}{2}\left[E_{c}(T)+E_{m}(T)\right]\left(1-\frac{2|z|}{h}\right), \\
\rho(z, T)= & {\left[\rho_{c}(T)-\rho_{m}(T)\right]\left(\frac{z}{h}+\frac{1}{2}\right)^{p} } \\
& +\rho_{m}(T)-\frac{\zeta}{2}\left[\rho_{c}(T)+\rho_{m}(T)\right]\left(1-\frac{2|z|}{h}\right), \\
\alpha(z, T)= & {\left[\alpha_{c}(T)-\alpha_{m}(T)\right]\left(\frac{z}{h}+\frac{1}{2}\right)^{p} } \\
& +\alpha_{m}(T)-\frac{\zeta}{2}\left[\alpha_{c}(T)+\alpha_{m}(T)\right]\left(1-\frac{2|z|}{h}\right), \\
& +v_{m}(T)-\frac{\zeta}{2}\left[\nu_{c}(T)+v_{m}(T)\right]\left(1-\frac{2|z|}{h}\right) .
\end{aligned}
$$

The variations of Young's modulus through the P-FGB thickness, corresponding to both kinds of porosity distribution, are presented in Figures 4 and 5. In Figure 4, in which the porosity is uniformly distributed, a regular decrease in Young's modulus is observed in the beam cross-section. 
TABle 1: Temperature-dependent coefficients of Young's modulus $(E)$, Thermal expansion coefficient $(\alpha)$, mass density $(\rho)$, and Poisson's ratio $(v)$ for silicone nitrite $\mathrm{Si}_{3} \mathrm{~N}_{4}$ and stainless steel SUS304.

\begin{tabular}{lcccccc}
\hline Material & Properties & $P_{0}$ & $P_{-1}$ & $P_{1}$ & $P_{2}$ & $P_{3}$ \\
\hline & $E(\mathrm{~Pa})$ & $348.43 \mathrm{e}+9$ & 0 & $-3.070 \mathrm{e}-4$ & $2.160 \mathrm{e}-7$ & $-8.946 \mathrm{e}-11$ \\
Ceramic silicone nitrite $\mathrm{Si}_{3} \mathrm{~N}_{4}$ & $\alpha\left(\mathrm{K}^{-1}\right)$ & $5.8723 \mathrm{e}-6$ & 0 & $9.095 \mathrm{e}-4$ & 0 & 0 \\
& $\rho\left(\mathrm{Kg} / \mathrm{m}^{3}\right)$ & 2370 & 0 & 0 & 0 & 0 \\
& $v$ & 0.24 & 0 & 0 & 0 & 0 \\
Metal stainless steel SUS304 & $E(\mathrm{~Pa})$ & $201.04 \mathrm{e}+9$ & 0 & $3.079 \mathrm{e}-4$ & $-6.534 \mathrm{e}-7$ & 0 \\
& $\alpha\left(\mathrm{K}^{-1}\right)$ & $12.330 \mathrm{e}-6$ & 0 & $8.086 \mathrm{e}-4$ & 0 & 0 \\
& $\rho\left(\mathrm{Kg} / \mathrm{m}^{3}\right)$ & 8166 & 0 & 0 & 0 & 0 \\
\hline
\end{tabular}

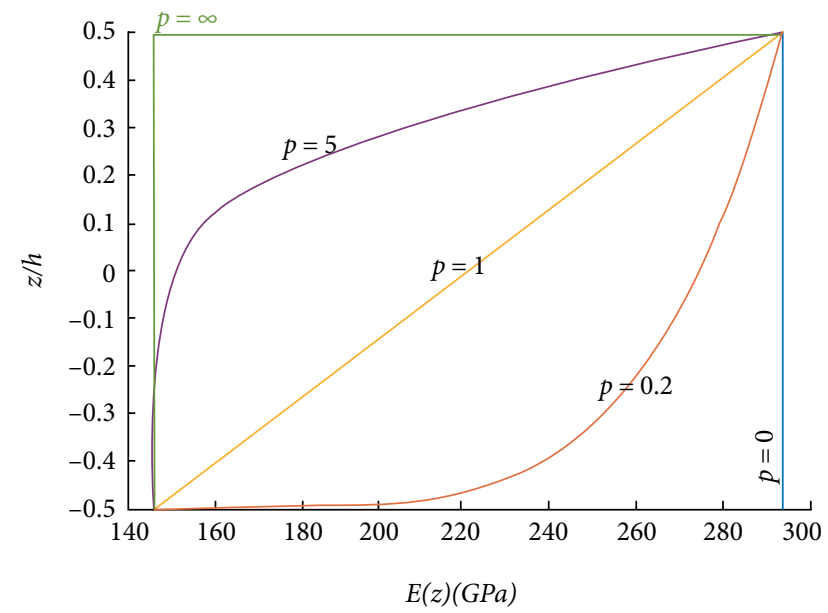

FIGURE 4: Variation of Young's modulus through the P-FGB thickness for different values of the gradient index $(p)$ : first kind of porosity distribution for $(\zeta=0.2)$.

In Figure 5, in which the porosities are concentrated around the middle zone of the cross section, a higher decrease in Young's modulus is observed in this zone.

Figure 6 shows a comparison of Young's modulus of the perfect (without porosities) and porous FGB in both kinds of porosity distributions.

2.4. Temperature Distribution. In order to accurately describe the effect of the temperature rise through the P-FGB thickness, different temperature distributions (see Figure 7) are taken into account in the present analysis, i.e., uniform (UTR), linear (LTR), and sinusoidal (STR) temperature distributions. Each case is accurately defined below.

2.4.1. Uniform Temperature Rise (UTR). The reference temperature is $T_{0}=300^{\circ} \mathrm{K}$. At $T_{0}$, the P-FGB is free of stresses and the temperature is uniformly raised to a final temperature $T$, with $\Delta T$ defined by:

$$
\Delta T=T-T_{0} .
$$

2.4.2. Linear Temperature Rise (LTR). The temperature of the top surface (Ceramic-rich) of the beam is $T_{C}$ and varies linearly from $T_{C}$ to the bottom surface (Metal-rich) temperature $T_{m}$. Therefore, the temperature rise through the thickness is given by [70]:

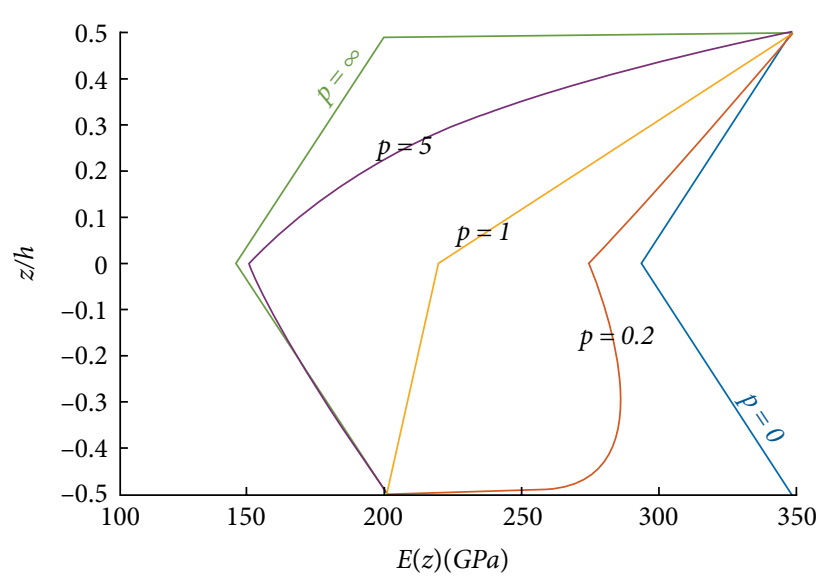

FIGURE 5: Variation of Young's modulus through the P-FGB thickness for different values of the gradient index $(p)$ : second kind of porosity distribution for $(\zeta=0.2)$.

$$
T=T_{m}+\Delta T\left(\frac{z}{h}+\frac{1}{2}\right) ; \quad \Delta T=T_{c}-T_{m} .
$$

2.4.3. Sinusoidal Temperature Rise (STR). The temperature distribution across the thickness direction follows a sinusoidal variation as in [71]:

$$
T(z)=T_{m}+\Delta T\left(1-\cos \left[\frac{\pi}{2}\left(\frac{z}{h}+\frac{1}{2}\right)\right]\right), \quad \Delta T=T_{c}-T_{m} .
$$

\section{General Theory}

3.1. Displacement Field of the Beam. According to the Refined Higher-order Shear Deformation Theory (RHSDT), the axial and transverse displacements of the beam are given by:

$$
\begin{gathered}
U(x, z, t)=u_{0}(x, t)-z \frac{\partial w_{b}}{\partial x}-f(z) \frac{\partial w_{s}}{\partial x}, \\
W(x, z, t)=w_{b}(x, t)+w_{s}(x, t) .
\end{gathered}
$$

In which $u_{0}$ is the axial displacement of a current point of the beam mid-line along the $x$-axis. $w_{b}, w_{s}$ are the corresponding bending and shear components of the transverse displacement and $t$ is the time. 


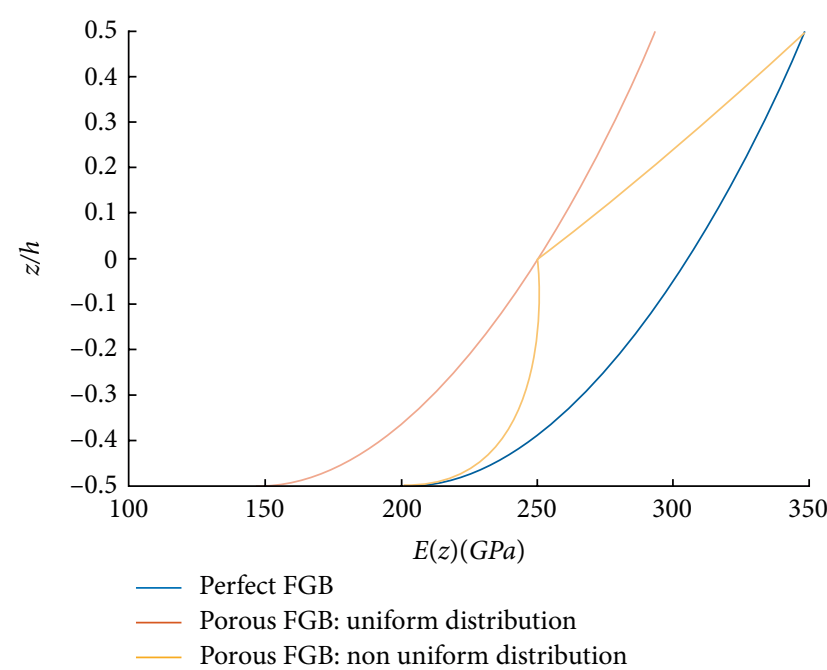

FIGURE 6: Comparison of the variation of Young's modulus through the P-FGB thickness for both kinds of porosity distributions for $(p=0.5)$ and $(\zeta=0.2)$.

The shape function $f(z)$ defines the distributions of the transverse shear strain and shear stress through the beam thickness. This function is chosen to satisfy the stress-free boundary conditions on the top and bottom surfaces of the beam. So, it does not require use of any shear correction factor. Based on the hyperbolic shear deformation theory proposed by Zenkour [72], the shape function $f(z)$ can be expressed as:

$$
f(z)=z-h \sin h\left(\frac{z}{h}\right)+\left[\cos \left(\frac{1}{2}\right)\right] \frac{4 z^{3}}{h^{2}} .
$$

The nonzero strains associated with the displacement field in Equations (13a) and (13b) can be expressed as follows:

$$
\begin{aligned}
& \varepsilon_{x x}=\frac{\partial U}{\partial x}=\frac{\partial u_{0}}{\partial x}-z \frac{\partial^{2} w_{b}}{\partial x^{2}}-f(z) \frac{\partial^{2} w_{s}}{\partial x^{2}}, \\
& \gamma_{x z}=g(z) \frac{\partial w_{s}}{\partial x} ; \quad g(z)=\left(1-\frac{d f(z)}{d z}\right),
\end{aligned}
$$

where $\varepsilon_{x x}$ and $\gamma_{x z}$ are the normal and shear strains respectively.

By assuming that the material of P-FGB obeys Hooke's law, the following linear elastic constitutive equation can be written as:

$$
\left\{\begin{array}{l}
\sigma_{x x} \\
\sigma_{x z}
\end{array}\right\}=\left[\begin{array}{cc}
E(z, T) & 0 \\
0 & G(z, T)
\end{array}\right]\left\{\begin{array}{l}
\varepsilon_{x x} \\
\gamma_{x z}
\end{array}\right\},
$$

where $G(z, T)$ is the Shear modulus related to Young's modulus $E(z, T)$ by:

$$
G(z, T)=\frac{E(z, T)}{2(1+v(z, T))} .
$$

3.2. Governing Equations. Hamilton's principle has been used herein to derive the equations of motion. The principle can be stated in an analytical form as follows:

$$
\int_{t_{1}}^{t_{2}}\left(\delta \mathscr{K}-\delta \mathscr{U}-\delta \mathscr{U}_{e f}+\delta \mathscr{V}\right) d t=0,
$$

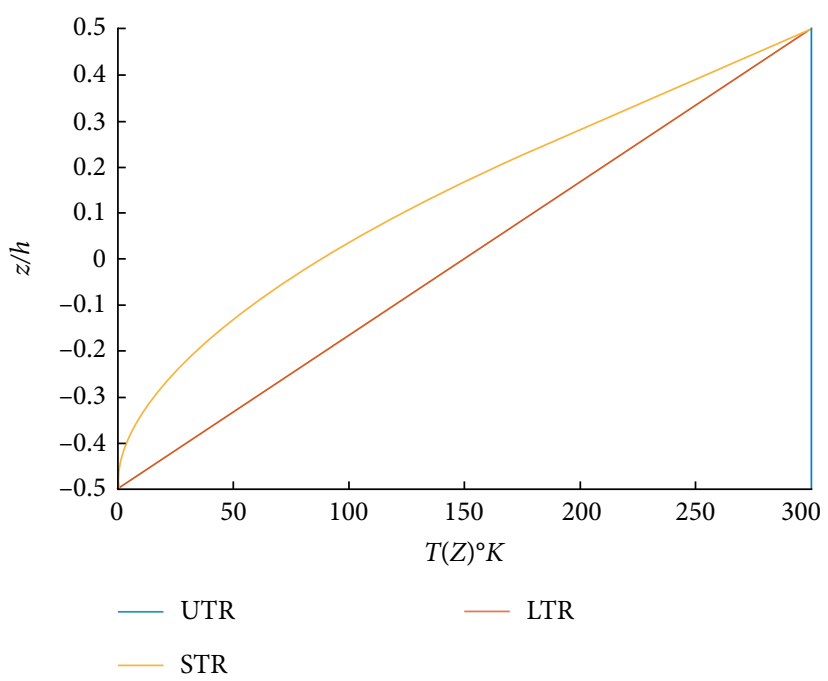

FIgURE 7: Profile of the three temperature distributions through the P-FGB thickness.

in which $t_{1}, t_{2}$ are the initial and end time, $\mathscr{U}$ is the beam strain energy, $\mathscr{U}_{e f}$ is the potential energy of the elastic foundation, $\mathscr{V}$ is the load potential, and $\mathscr{K}$ is the kinetic energy.

(i) The variation of the Kinetic energy of the P-FGB can be expressed as follows:

$$
\begin{aligned}
\delta \mathscr{K}= & \int_{0}^{L} \int_{-h / 2}^{h / 2} \rho(z)(\dot{U} \delta \dot{U}+\dot{W} \delta \dot{W}) b d z d x \\
= & \int_{0}^{L}\left\{I_{0}\left[\dot{u}_{0} \delta \dot{u}_{0}+\left(\dot{w}_{b}+\dot{w}_{s}\right)\left(\delta \dot{w}_{b}+\delta \dot{w}_{s}\right)\right]\right. \\
& -I_{1}\left[\dot{u}_{0} \frac{\partial \delta \dot{w}_{b}}{\partial x}+\frac{\partial \dot{w}_{b}}{\partial x} \delta \dot{u}_{0}\right]+I_{2} \frac{\partial \dot{w}_{b}}{\partial x} \frac{\partial \delta \dot{w}_{b}}{\partial x} \\
& -J_{1}\left[\dot{u}_{0} \frac{\partial \delta \dot{w}_{s}}{\partial x}+\frac{\partial \dot{w}_{s}}{\partial x} \delta \dot{u}_{0}\right] \\
& +J_{2}\left[\frac{\partial \dot{w}_{b}}{\partial x} \frac{\partial \delta \dot{w}_{s}}{\partial x}+\frac{\partial \dot{w}_{s}}{\partial x} \frac{\partial \delta \dot{w}_{b}}{\partial x}\right] \\
& \left.+K_{2} \frac{\partial \dot{w}_{s}}{\partial x} \frac{\partial \delta \dot{w}_{s}}{\partial x}\right\} d x
\end{aligned}
$$

where $\left(I_{0}, I_{1}, I_{2}, J_{1}, J_{2}, K_{2}\right)$ are mass inertias, defined as follows:

$$
\begin{gathered}
\left(I_{0}, I_{1}, I_{2}\right)=\int_{-h / 2}^{h / 2}\left(1, z, z^{2}\right) \rho(z) b d z \\
\left(J_{1}, J_{2}, K_{2}\right)=\int_{-h / 2}^{h / 2}\left(f, z f, f^{2}\right) \rho(z) b d z .
\end{gathered}
$$

The dot-superscript convention corresponds to differentiation with respect to the time variable $(t)$.

(ii) The variation of the strain energy $\mathscr{U}$ of the P-FGB is calculated by: 


$$
\begin{aligned}
\delta \mathscr{U} & =\int_{0}^{L} \int_{-h / 2}^{h / 2}\left(\sigma_{x x} \delta \varepsilon_{x x}+\sigma_{x z} \delta \gamma_{x z}\right) b d z d x \\
& =\int_{0}^{L}\left(N \frac{\partial \delta u_{0}}{\partial x}-M_{b} \frac{\partial^{2} \delta w_{b}}{\partial x^{2}}-M_{s} \frac{\partial^{2} \delta w_{s}}{\partial x^{2}}+Q \frac{\partial \delta w_{s}}{\partial x}\right) b d x
\end{aligned}
$$

where $N, M_{b}, M_{s}$, and $Q$ are the stress resultants, defined as:

$$
\begin{gathered}
\left(N, M_{b}, M_{s}\right)=\int_{-h / 2}^{h / 2} \sigma_{x x}(1, z, f(z)) d z \\
Q=\int_{-h / 2}^{h / 2} \sigma_{x z} g(z) d z
\end{gathered}
$$

Using Equations (16a), (16b), (19a), and (19b), the stress resultants can be expressed as:

$$
\left\{\begin{array}{c}
N \\
M_{b} \\
M_{s} \\
Q
\end{array}\right\}=\left[\begin{array}{cccc}
A & B & B_{s} & 0 \\
B & D & D_{s} & 0 \\
B_{s} & D_{s} & H_{s} & 0 \\
0 & 0 & 0 & A_{s}
\end{array}\right]\left\{\begin{array}{c}
\frac{\partial u_{0}}{\partial x} \\
-\frac{\partial^{2} w_{b}}{\partial x^{2}} \\
-\frac{\partial^{2} w_{s}}{\partial x^{2}} \\
\frac{\partial w_{s}}{\partial x}
\end{array}\right\}
$$

where $\left(A, B, D, B_{s}, D_{s}, H_{s}, A_{s}\right)$ are the P-FGB stiffness, defined by:

$$
\begin{aligned}
(A, B, D) & =\int_{-h / 2}^{h / 2}\left(1, z, z^{2}\right) E(z, T) d z, \\
\left(B_{s}, D_{s}, H_{s}\right) & =\int_{-h / 2}^{h / 2}\left(f, z f, f^{2}\right) E(z, T) d z, \\
A_{s} & =\int_{-h / 2}^{h / 2} g^{2} G(z, T) d z .
\end{aligned}
$$

(iii) The variation of the potential energy of the elastic foundation is expressed as follows:

$$
\delta \mathscr{U}_{e f}=\int_{0}^{L}\left(k_{w} W \delta W+k_{p} \frac{\partial W}{\partial x} \delta W\right) b d x .
$$

The applied external load, denoted by $\overline{N^{T}}$, is considered to be due only to the thermal environment. The variation of this potential load can be expressed as follows:

$$
\delta \mathscr{V}=\int_{0}^{L} \overline{N^{T}} \frac{\partial\left(w_{b}+w_{s}\right)}{\partial x} \frac{\partial \delta\left(w_{b}+w_{s}\right)}{\partial x} b d x
$$

in which $\overline{N^{T}}$ is defined by:

$$
\overline{N^{T}}=\int_{-h / 2}^{h / 2} E(z, T) \alpha(z, T) \Delta T d z
$$

where $\alpha$ is the thermal expansion coefficient that is typically positive and very small, and $\Delta T$ is the temperature difference defined previously for each temperature field.
3.3. Boundary Conditions. In this study, we are concerned with the analytical solution for a hard simply supported P-FGB. In this case, both ends of the beam are not free to move towards the longitudinal direction. Thus, the following conditions are imposed:

$$
\begin{aligned}
\text { at } x & =0, L \\
u_{0} & =w_{b}=w_{s}=0 \\
N & =0 \text { or } A \frac{\partial u_{0}}{\partial x}-B \frac{\partial^{2} w_{b}}{\partial x^{2}}-B_{s} \frac{\partial^{2} w_{s}}{\partial x^{2}}=0 \\
M_{b} & =0 \text { or } B \frac{\partial u_{0}}{\partial x}-D \frac{\partial^{2} w_{b}}{\partial x^{2}}-D_{s} \frac{\partial^{2} w_{s}}{\partial x^{2}}=0 \\
M_{s} & =0 \text { or } B_{s} \frac{\partial u_{0}}{\partial x}-D_{s} \frac{\partial^{2} w_{b}}{\partial x^{2}}-H_{s} \frac{\partial^{2} w_{s}}{\partial x^{2}}=0 \\
Q & =0 \text { or } A_{s} \frac{\partial w_{s}}{\partial x}=0
\end{aligned}
$$

Substituting the expressions for $\delta \mathscr{U}, \delta \mathscr{U}_{\text {ef }}, \delta \mathscr{V}$ and $\delta \mathscr{K}$ from Equations (18), (20), (24) and (25) into Equation (17), the following equations of motion are obtained by integrations by parts taking into account the previous boundary conditions, and putting together the coefficients of $\delta u_{0}, \delta w_{b}$, and $\delta w_{s}$.

$$
\begin{gathered}
\delta u_{0}: \frac{\partial N}{\partial x}=I_{0} \ddot{u}_{0}-I_{1} \frac{\partial \ddot{w}_{b}}{\partial x}-J_{1} \frac{\partial \ddot{w}_{s}}{\partial x} \\
\delta w_{b}: \frac{\partial^{2} M_{b}}{\partial x^{2}}+\overline{N^{T}} \frac{\partial^{2}\left(w_{b}+w_{s}\right)}{\partial x^{2}}-K_{p} \frac{\partial^{2}\left(w_{b}+w_{s}\right)}{\partial x^{2}} \\
+K_{w}\left(w_{b}+w_{s}\right)=-I_{0}\left(\ddot{w}_{b}+\ddot{w}_{s}\right) \\
\quad-I_{1} \frac{\partial \ddot{u}_{0}}{\partial x}+I_{2} \frac{\partial^{2} \ddot{w}_{b}}{\partial x^{2}}+J_{2} \frac{\partial^{2} \ddot{w}_{s}}{\partial x^{2}} \\
\delta w_{s}: \frac{\partial^{2} M_{s}}{\partial x^{2}}-\frac{\partial Q}{\partial x}+\frac{\overline{N^{T}}}{\partial^{2}\left(w_{b}+w_{s}\right)} \\
-K_{p} \frac{\partial^{2}\left(w_{b}+w_{s}\right)}{\partial x^{2}}+K_{w}\left(w_{b}+w_{s}\right) \\
=-I_{0}\left(\ddot{w}_{b}+\ddot{w}_{s}\right)-J_{1} \frac{\partial \ddot{u}_{0}}{\partial x}+J_{2} \frac{\partial^{2} \ddot{w}_{b}}{\partial x^{2}}-K_{2} \frac{\partial^{2} \ddot{w}_{s}}{\partial x^{2}} .
\end{gathered}
$$

Eqs. (28a), (28b), and (28c) can be expressed in terms of the displacements $u_{0}, w_{b}$ and $w_{s}$ by using Eq. (20) as follows:

$$
\delta u_{0}: A \frac{\partial^{2} u_{0}}{\partial x^{2}}-B \frac{\partial^{3} w_{b}}{\partial x^{3}}-B_{s} \frac{\partial^{3} w_{s}}{\partial x^{3}}=I_{0} \ddot{u}_{0}-I_{1} \frac{\partial \ddot{w}_{b}}{\partial x}-J_{1} \frac{\partial \ddot{w}_{s}}{\partial x}
$$

$$
\begin{aligned}
\delta w_{b}: & B \frac{\partial^{3} u_{0}}{\partial x^{3}}-D \frac{\partial^{4} w_{b}}{\partial x^{4}}-D_{s} \frac{\partial^{4} w_{s}}{\partial x^{4}}-\overline{N^{T}} \frac{\partial^{2}\left(w_{b}+w_{s}\right)}{\partial x^{2}} \\
& +K_{p} \frac{\partial^{2}\left(w_{b}+w_{s}\right)}{\partial x^{2}}-K_{w}\left(w_{b}+w_{s}\right)=I_{0}\left(\ddot{w}_{b}+\ddot{w}_{s}\right) \\
& +I_{1} \frac{\partial \ddot{u}_{0}}{\partial x}-I_{2} \frac{\partial^{2} \ddot{w}_{b}}{\partial x^{2}}-J_{2} \frac{\partial^{2} \ddot{w}_{s}}{\partial x^{2}},
\end{aligned}
$$




$$
\begin{aligned}
\delta w_{s}: & B_{s} \frac{\partial^{3} u_{0}}{\partial x^{3}}-D_{s} \frac{\partial^{4} w_{b}}{\partial x^{4}}-H_{s} \frac{\partial^{4} w_{s}}{\partial x^{4}} \\
& -A_{s} \frac{\partial^{2} w_{s}}{\partial x^{2}}-\overline{N^{T}} \frac{\partial^{2}\left(w_{b}+w_{s}\right)}{\partial x^{2}}+K_{p} \frac{\partial^{2}\left(w_{b}+w_{s}\right)}{\partial x^{2}} \\
& -K_{w}\left(w_{b}+w_{s}\right)=I_{0}\left(\ddot{w}_{b}+\ddot{w}_{s}\right)+J_{1} \frac{\partial \ddot{u}_{0}}{\partial x}-J_{2} \frac{\partial^{2} \ddot{w}_{b}}{\partial x^{2}} \\
& -K_{2} \frac{\partial^{2} \ddot{w}_{s}}{\partial x^{2}} .
\end{aligned}
$$

3.4. Analytical Solution for a Simply Supported P-FGB. An analytical solution, based on the Navier type method of the equations of motion of a simply supported P-FGB is provided. The displacement variables $u_{0}, w_{b}$, and $w_{s}$ are expanded as combinations of unknown coefficients, that will be determined for each value of " $n$ ", multiplied by known trigonometric functions satisfying the governing equations and end conditions. The displacements are written as:

$$
\left[\begin{array}{c}
u_{0}(x, t) \\
w_{b}(x, t) \\
w_{s}(x, t)
\end{array}\right]=\sum_{n=1}^{\infty}\left[\begin{array}{c}
U_{n} \cos (\lambda x) e^{i \omega_{n} t} \\
W_{b n} \sin (\lambda x) e^{i \omega_{n} t} \\
W_{s n} \sin (\lambda x) e^{i \omega_{n} t}
\end{array}\right],
$$

in which $\omega_{n}$ is the eigen frequency associated with the $n^{\text {th }}$ eigen mode, $\lambda=n \pi / L$, and $U_{n}, W_{b n}, W_{s n}$ are the unknown coefficients that will be determined for each value of " $n$ ". Substituting Eq. (30) into Eq. (29) leads to the following Equations:

$$
\begin{gathered}
-A \lambda^{2} U_{n}+B \lambda^{3} W_{b n}-B_{s} \lambda^{3} W_{s n}-\omega_{n}^{2}\left[-I_{0} U_{n}+I_{1} \lambda W_{b n}+J_{1} \lambda W_{s n}\right]=0, \\
B \lambda^{3} U_{n}+\left(\overline{N^{T}} \lambda^{2}-D \lambda^{2}+K_{p} \lambda^{2}+K_{w}\right) \\
W_{b n}+\left(\overline{N^{T}} \lambda^{2}-D_{s} \lambda^{4}+K_{p} \lambda^{2}+K_{w}\right) W_{s n} \\
\quad-\omega_{n}^{2}\left[I_{1} \lambda U_{n}-\left(I_{0}+I_{2} \lambda^{2}\right) W_{b n}-\left(I_{0}+J_{2} \lambda^{2}\right) W_{s n}\right]=0, \\
B_{s} \lambda^{3} U_{n}+\left(\overline{N^{T}} \lambda^{2}-D_{s} \lambda^{4}+K_{p} \lambda^{2}+K_{w}\right) W_{b n} \\
+\left(\overline{N^{T}} \lambda^{2}-H_{s} \lambda^{4}-A_{s} \lambda^{2}+K_{p} \lambda^{2}+K_{w}\right) W_{s n} \\
\quad-\omega_{n}^{2}\left[J_{1} \lambda U_{n}-\left(I_{0}+J_{2} \lambda^{2}\right) W_{b n}-\left(I_{0}+K_{2} \lambda^{2}\right) W_{s n}\right]=0 .
\end{gathered}
$$

Analytical solutions may be obtained from the eigenvalue system below for any fixed value of " $n$ ":

$$
\left([\mathrm{K}]-\omega_{n}^{2}[\mathrm{M}]\right)\{\Delta\}=\{0\},
$$

where,

$$
\begin{aligned}
& {[K]=\left[\begin{array}{lll}
a_{11} & a_{12} & a_{13} \\
a_{12} & a_{22} & a_{23} \\
a_{13} & a_{23} & a_{33}
\end{array}\right] ;} \\
& {[M]=\left[\begin{array}{lll}
m_{11} & m_{12} & m_{13} \\
m_{12} & m_{22} & m_{23} \\
m_{13} & m_{23} & m_{33}
\end{array}\right] ;} \\
& \{\Delta\}=\left\{\begin{array}{c}
U_{n} \\
W_{b n} \\
W_{s n}
\end{array}\right\},
\end{aligned}
$$

in which

$$
\begin{aligned}
& a_{11}=-A \lambda^{2} ; \\
& a_{12}=B \lambda^{3} ; \\
& a_{13}=B \lambda_{s} \lambda^{3} \\
& a_{22}=\overline{N^{T}} \lambda^{2}-D \lambda^{4}+K_{p} \lambda^{2}+K_{w}, \\
& a_{23}=\overline{N^{T}} \lambda^{2}-D_{s} \lambda^{4}+K_{p} \lambda^{2}+K_{w}, \\
& a_{33}=\overline{N^{T}} \lambda^{2}-H_{s} \lambda^{4}-A_{s} \lambda^{2}+K_{p} \lambda^{2}+K_{w}, \\
& m_{11}=-I_{0} ; \\
& m_{12}=I_{1} \lambda ; \\
& m_{13}=J_{1} \lambda \\
& m_{22}=-I_{0}-I_{2} \lambda^{2} ; \\
& m_{23}=-I_{0}-J_{2} \lambda^{2} ; \\
& m_{33}=-I_{0}-K_{2} \lambda^{2} ;
\end{aligned}
$$

\section{Numerical Results and Discussion}

The P-FGB examined is made of Steel (SUS304) and Silicon nitride $\left(\mathrm{Si}_{3} \mathrm{~N}_{4}\right)$ whose properties are given in Table 1. It is supposed that the temperature rise at the fully metal surface from the reference temperature $T_{0}$ of the beam is $T_{m}-T_{0}=5^{\circ} \mathrm{K}[67]$.

The nondimensional natural frequencies can be calculated by the following relation:

$$
\overline{\omega_{n}}=\omega_{n} \frac{L^{2}}{h} \sqrt{\frac{\rho_{m}}{E_{m}}} .
$$

In Table 2, numerical results obtained here for the nondimensional natural frequencies are compared with results of Ebrahimi and Jafari [59], based on the Differential Transform Method (DTM) used to solve the equations of motions, and with result of Simsek [73], obtained using Lagrange's equations.

The shape function used in both works is based on the Reddy beam theory and defined as:

$$
f(z)=\frac{4 z^{3}}{3 h^{2}} \text {. }
$$

The material constituents of the FG beam used are ceramic "Alumina $\left(\mathrm{Al}_{2} \mathrm{O}_{3}\right)$ " and metal "Aluminum $(\mathrm{Al})$ ", with the following material properties:

Alumina $\left(\mathrm{Al}_{2} \mathrm{O}_{3}\right):\left(E_{c}=380 \mathrm{GPa}, \rho_{c}=3960 \mathrm{Kg} / \mathrm{m}^{3}, v_{c}=0.3\right)$.

Aluminum $(A l):\left(E_{m}=70 \mathrm{GPa}, \rho_{m}=2702 \mathrm{Kg} / \mathrm{m}^{3}, v_{m}=0.3\right)$.

It is observed that the fundamental frequency parameters obtained in the present work are in a good agreement with the published results, which validates the present approach.

As a first verification and illustration example, the effects of the power law exponent and the slenderness ratio on the fundamental nondimensional frequency of the simply supported P-FGB are evaluated.

The variation of dimensionless fundamental frequencies in terms of the power law index is plotted in Figure 8. It can be seen from this figure that the frequencies decrease with the increase in the power-law index. In fact, increasing the 
TABLE 2: Comparison of the dimensionless fundamental frequency $\left(\bar{\omega}_{1}\right)$ of perfect simply-supported FGB for $\Delta T=0^{\circ} \mathrm{K}$.

\begin{tabular}{|c|c|c|c|c|c|c|c|}
\hline$L / h$ & \multicolumn{2}{|c|}{ Solution method } & \multicolumn{5}{|c|}{$p$} \\
\hline \multirow{3}{*}{5} & Ebrahimi and Jafari [59] & DTM & 5.1524 & 4.8060 & 4.4106 & 3.9965 & 3.6447 \\
\hline & Simsek [73] & Lagrange's equations & 5.1524 & 4.8065 & 4.4083 & 3.9902 & 3.6343 \\
\hline & Present & Navier solution & 5.1527 & 4.8080 & 4.4106 & 3.9904 & 3.6264 \\
\hline \multirow{3}{*}{20} & Ebrahimi and Jafari [59] & DTM & 5.4603 & 5.0813 & 4.6511 & 4.2055 & 3.8375 \\
\hline & Simsek [73] & Lagrange's equations & 5.4603 & 5.0826 & 4.6513 & 4.2050 & 3.8367 \\
\hline & Present & Navier solution & 5.4603 & 5.0815 & 4.6511 & 4.2050 & 3.8361 \\
\hline
\end{tabular}

material index from 0 to 10 changes the composition of the FG beam from a fully ceramic beam to a beam with a combination of ceramic and metal. By increasing the metal composition, the stiffness of the structure decreases because of the smaller value of the metal's Young's modulus, compared with that of ceramic. Also, in this kind of composition, the density of the metal is greater than the density of ceramic and the total mass of the FG beam increases by increasing the metal proportion in the beam, which makes it softer. Therefore, the frequency decreases by increasing the material index $p$.

Figure 9 shows the nondimensional frequency versus the slenderness ratio for a constant value of the power law index. It can be found that increasing the slenderness ratio yields a decrease in the frequencies, and this decrease grows with the increase in temperature.

It can be seen also in Figure 10 that the full ceramic beam $(p=0)$ has the highest frequency and the full metallic beam $(p \rightarrow \infty)$ has the lowest frequency. This is due to the fact that an increase in the value of the power law index results in a decrease in the elasticity modulus. In other words, the beam becomes more flexible as the volume fraction exponent increases, inducing a decrease in the natural frequencies.

The results given below correspond to various values of the temperature change, the power-law index, the porosity parameters for three types of temperature rise, i.e., UTR, LTR, and STR and two porosity distributions, i.e., uniform and nonuniform. The results given in Tables 3(a) and 3(b) show that the natural frequencies of P-FGB decrease with increasing the power-law exponents. In fact, when $p$ is zero, the beam is fully ceramic and has the greatest frequency. By increasing $p$, the composition of the P-FGB changes from a fully ceramic beam to a beam with a combination of ceramic and metal, which results in a decrease in the natural frequencies, as explained above. These Tables show also that increasing the temperature for different types of thermal loads (UTR, LTR, and STR) yields a decrease in the natural frequencies. It is clear that increasing the temperature yields a decrease in Young's modulus and this effect is more accentuated at higher temperatures. So the effect of the temperature change on the natural frequencies cannot be neglected. It is found from both the tables that the natural frequencies of P-FGB subjected to a sinusoidal temperature rise are higher than that under a linear or a uniform temperature rise. Also the difference between the frequencies of the three types of thermal loads UTR, LTR, and STR becomes larger by increasing the temperature change.

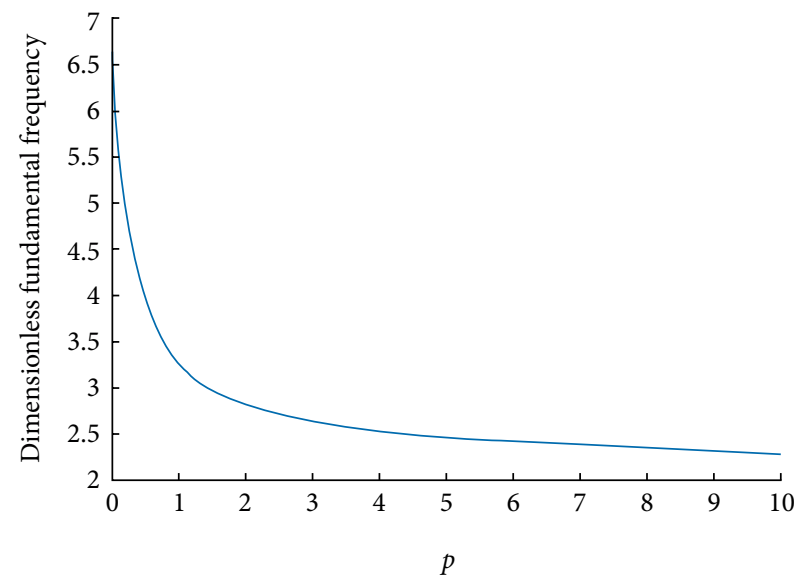

FIGURE 8: Effect of the power-law index $(p)$ on the dimensionless fundamental frequency of P-FGB subjected to sinusoidal temperature rise $\left(\Delta T=100^{\circ} \mathrm{K}\right)$ for $L / h=20$ and $\zeta=0.2$.

The reason is that, over other cases of thermal loads, rigidity of the P-FGB for sinusoidal thermal load is greatest.

According to results of these tables, it can be seen that, when the percentage of the metal is lower than ceramic $(p<1)$ the frequencies increase with increase in the porosity index for the three thermal loads and both porosity distributions. The increase of internal pores in the P-FGBs increases their rigidity, and this situation is more eminent for lower values of the power-law index. Also, at constant temperature when the percentage of the metal is higher than ceramic $(p>1)$ the fundamental frequencies decrease by increasing the porosity index for both porosity distributions.

Comparing the frequency of P-FGB with a uniform and a nonuniform porosity distribution revealed that when the power-law index is in the range of [0-0.5], natural frequencies of a uniform porosity distribution are higher than a nonuniform porosity distribution. Unlike in the case where the power-law index is greater than 0.5 . At constant values of the temperature and the gradient index, the changes in the porosity index lead to more variations in frequencies for a uniform distribution in comparison with a nonuniform distribution. So, the impact on the natural frequencies of P-FGB is more significant with a uniform than with a nonuniform porosity distribution.

To show the impact of temperature on the frequencies, Figure 11 presents the dimensionless natural frequency variation versus the temperature, for various power-law indexes and a constant value of slenderness ratio. The beam with a uniform 


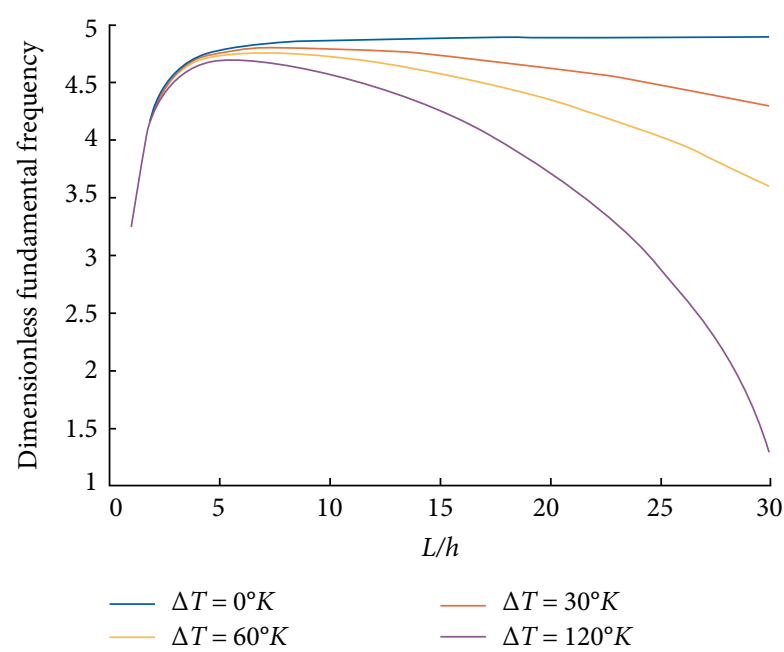

FIGURE 9: Effect of slenderness ratio $(L / h)$ on the dimensionless fundamental frequency of P-FGB subjected to sinusoidal temperature rise for different values of $\Delta T . p=0.5, \zeta=0.2$.

porosity distribution is subjected to a uniform temperature rise. As can be seen, for all gradient indexes the natural frequency decreases with the increase in the temperature until it gets to near zero, where the critical temperature corresponding to the buckling temperature of the beam. This is because of the increment in total flexibility of the beam, considering geometrical stiffness decreases when temperature rises. On the other hand, after this critical temperature this behavior is vice versa. Furthermore, the temperature change can soften P-FGB at pre-buckling region in a way that when the temperature rises this effect will be increased. It is observed also from the results of this figure that if the power-law index increases, the buckling temperature and natural frequency of P-FGB will decrease.

To display the impact of the porosity volume fractions with a uniform porosity distribution on the buckling temperature and natural frequency, Figure 12 presents the frequency results versus the temperature for various porosity parameters at constant values of the slenderness ratio and power-law index. The higher natural frequencies are obtained before the buckling temperature for the higher value of porosity index. This behavior is reversed after this temperature. It can be so stated that the temperature rise can bring P-FGB to buckling. As it is shown in this figure, an increase of the porosity parameter leads a decrease in the buckling temperature, because the higher porosity indexes will cause an increase of structure stiffness.

The effect of the thermal field type on the frequencies is plotted in Figure 13. The beam with a uniform porosity distribution is subjected to three thermal loadings (UTR, LTR, and STR) for constant values of the porosity volume fraction, the power law index, and the slenderness ratio. It can be found that the buckling temperature of P-FGB subjected to STR is higher than the other temperature risings.

Figure 14 displays the variations of the dimensionless natural frequencies of P-FGB with a uniform porosity distribution versus the temperature, for different values of the slenderness ratio, and constant values of the porosity volume fraction and the power law index. The beam is subjected to a uniform

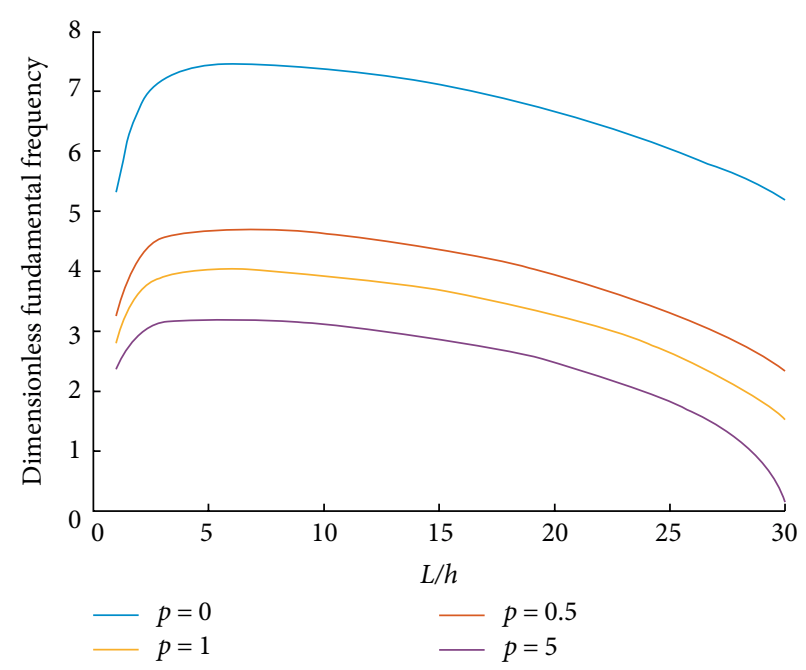

FIgURE 10: Effect of slenderness ratio $(L / h)$ on dimensionless fundamental frequency of P-FGB subjected to sinusoidal temperature rise for different values of $p\left(\Delta T=100^{\circ} \mathrm{K}\right), \zeta=0.2$.

temperature rise. It can be found that the buckling temperature decreases with the increase in the slenderness ratio. As it is also known for the buckling of straight beams, the Euler critical-load decreases with increase in the beam slenderness ratio.

In order to analyze the influence of elastic foundations on the natural frequencies, Figures 15 and 16 present the variation of the nondimensional natural frequencies of P-FGB versus both elastic foundation parameters. The beam with a uniform porosity distribution is subjected to a uniform temperature rise.

Variation of dimensionless frequencies versus the Winkler's parameter by cancelling Pasternak's parameter, for different values of the porosity parameter is plotted in Figure 15. Then, this variation versus the Pasternak's parameter by cancelling Winkler's parameter, for different values of the porosity index is plotted in Figure 16. It can be seen from theses curves that, for any values of the porosity index, the natural frequencies increase with increasing the Winkler's and Pasternak's parameters. This is due to the fact that by increasing both elastic foundation parameters, the total stiffness of the system increases, and consequently the dimensionless frequencies increase. The higher frequencies are obtained for the higher value of porosity index.

As revealed by Figure 17, Pasternak's parameter exhibits more effects on natural frequencies than Winkler's parameter and the higher frequencies are obtained by combining both elastic foundation parameters.

\section{Conclusions}

The present work was concerned with the modelling of the dynamic behavior for Porous Functionally Graded Beams (P-FGB) resting on a two-parameter elastic foundation in a thermal environment. The FG Material properties were supposed to be temperature-dependent and to vary through the beam thickness according to a modified rule of mixture 
TABLE 3: Effect of the porosity volume fraction $\zeta$, the power law index $p$, and the thermal field on the fundamental dimensionless frequency of P-FGB, subjected to different temperature changes $\Delta T$ for $(L / h=20$.

(a) Uniform porosity distribution

\begin{tabular}{|c|c|c|c|c|c|c|c|c|c|}
\hline \multirow{2}{*}{$\Delta T$} & \multirow{2}{*}{ Porosity volume fraction $\zeta$} & \multirow{2}{*}{ Thermal load type } & \multicolumn{7}{|c|}{$p$} \\
\hline & & & 0 & 0.1 & 0.3 & 0.5 & 1 & 5 & 10 \\
\hline \multirow{9}{*}{$30^{\circ} \mathrm{K}$} & \multirow{3}{*}{0} & UTR & 6.5813 & 5.7743 & 4.8752 & 4.3840 & 3.7859 & 3.0276 & 2.8606 \\
\hline & & LTR & 6.6030 & 5.7923 & 4.8889 & 4.3953 & 3.7943 & 3.0330 & 2.8652 \\
\hline & & STR & 6.6167 & 5.8037 & 4.8976 & 4.4024 & 3.7995 & 3.0364 & 2.8681 \\
\hline & \multirow{3}{*}{0.1} & UTR & 7.2139 & 6.1576 & 5.0580 & 4.4839 & 3.8055 & 2.9805 & 2.8037 \\
\hline & & LTR & 7.2378 & 6.1768 & 5.0721 & 4.4951 & 3.8134 & 2.9852 & 2.8075 \\
\hline & & STR & 7.2530 & 6.1891 & 5.0810 & 4.5023 & 3.8184 & 2.9881 & 2.8099 \\
\hline & \multirow{3}{*}{0.2} & UTR & 8.2198 & 6.7060 & 5.2937 & 4.6038 & 3.8206 & 2.9161 & 2.7286 \\
\hline & & LTR & 8.2474 & 6.7271 & 5.3083 & 4.6150 & 3.8279 & 2.9198 & 2.7316 \\
\hline & & STR & 8.2650 & 6.7405 & 5.3176 & 4.6222 & 3.8325 & 2.9222 & 2.7334 \\
\hline \multirow{9}{*}{$60^{\circ} \mathrm{K}$} & \multirow{3}{*}{0} & UTR & 6.1875 & 5.3952 & 4.5128 & 4.0313 & 3.4468 & 2.7111 & 2.5452 \\
\hline & & LTR & 6.2437 & 5.4428 & 4.5505 & 4.0635 & 3.4724 & 2.7308 & 2.5633 \\
\hline & & STR & 6.2731 & 5.4676 & 4.5701 & 4.0801 & 3.4856 & 2.7408 & 2.5724 \\
\hline & \multirow{3}{*}{0.1} & UTR & 6.8441 & 5.8083 & 4.7299 & 4.1674 & 3.5043 & 2.7036 & 2.5283 \\
\hline & & LTR & 6.9050 & 5.8581 & 4.7678 & 4.1987 & 3.5281 & 2.7207 & 2.5438 \\
\hline & & STR & 6.9368 & 5.8842 & 4.7875 & 4.2150 & 3.5403 & 2.7293 & 2.5516 \\
\hline & \multirow{3}{*}{0.2} & UTR & 7.8658 & 6.3828 & 4.9985 & 4.3225 & 3.5568 & 2.6782 & 2.4928 \\
\hline & & LTR & 7.9347 & 6.4364 & 5.0370 & 4.3532 & 3.5785 & 2.6924 & 2.5054 \\
\hline & & STR & 7.9709 & 6.4645 & 5.0571 & 4.3692 & 3.5897 & 2.6996 & 2.5118 \\
\hline \multirow{9}{*}{$120^{\circ} \mathrm{K}$} & \multirow{3}{*}{0} & UTR & 5.3070 & 4.5322 & 3.6640 & 3.1873 & 2.6072 & 1.8767 & 1.6932 \\
\hline & & LTR & 5.4484 & 4.6581 & 3.7733 & 3.2882 & 2.6996 & 1.9680 & 1.7859 \\
\hline & & STR & 5.5174 & 4.7190 & 3.8254 & 3.3357 & 2.7422 & 2.0091 & 1.8273 \\
\hline & \multirow{3}{*}{0.1} & UTR & 6.0363 & 5.0317 & 3.9802 & 3.4289 & 2.7782 & 1.9954 & 1.8089 \\
\hline & & LTR & 6.1816 & 5.1563 & 4.0834 & 3.5213 & 2.8592 & 2.0716 & 1.8853 \\
\hline & & STR & 6.2531 & 5.2171 & 4.1330 & 3.5652 & 2.8968 & 2.1061 & 1.9196 \\
\hline & \multirow{3}{*}{0.2} & UTR & 7.1104 & 5.6809 & 4.3395 & 3.6816 & 2.9356 & 2.0850 & 1.8933 \\
\hline & & LTR & 7.2670 & 5.8079 & 4.4384 & 3.7668 & 3.0061 & 2.1477 & 1.9554 \\
\hline & & STR & 7.3450 & 5.8705 & 4.4864 & 3.8076 & 3.0391 & 2.1761 & 1.9834 \\
\hline
\end{tabular}

(b) Nonuniform porosity distribution

\begin{tabular}{|c|c|c|c|c|c|c|c|c|c|}
\hline \multirow{2}{*}{$\Delta T$} & \multirow{2}{*}{ Porosity volume fraction $\zeta$} & \multirow{2}{*}{ Thermal load type } & \multicolumn{7}{|c|}{$p$} \\
\hline & & & 0 & 0.1 & 0.3 & 0.5 & 1 & 5 & 10 \\
\hline \multirow{9}{*}{$30^{\circ} \mathrm{K}$} & \multirow{3}{*}{0} & UTR & 6.5813 & 5.7743 & 4.8752 & 4.3840 & 3.7859 & 3.0276 & 2.8606 \\
\hline & & LTR & 6.6030 & 5.7923 & 4.8889 & 4.3953 & 3.7943 & 3.0330 & 2.8652 \\
\hline & & STR & 6.6167 & 5.8037 & 4.8976 & 4.4024 & 3.7995 & 3.0364 & 2.8681 \\
\hline & \multirow{3}{*}{0.1} & UTR & 6.9423 & 6.0210 & 5.0258 & 4.4934 & 3.8542 & 3.0590 & 2.8869 \\
\hline & & LTR & 6.9650 & 6.0396 & 5.0397 & 4.5047 & 3.8624 & 3.0641 & 2.8913 \\
\hline & & STR & 6.9795 & 6.0514 & 5.0486 & 4.5119 & 3.8676 & 3.0673 & 2.8940 \\
\hline & \multirow{3}{*}{0.2} & UTR & 7.3775 & 6.3067 & 5.1932 & 4.6124 & 3.9261 & 3.0902 & 2.9129 \\
\hline & & LTR & 7.4015 & 6.3260 & 5.2074 & 4.6238 & 3.9342 & 3.0950 & 2.9169 \\
\hline & & STR & 7.4167 & 6.3383 & 5.2165 & 4.6310 & 3.9393 & 3.0981 & 2.9195 \\
\hline \multirow{9}{*}{$60^{\circ} \mathrm{K}$} & \multirow{3}{*}{0} & UTR & 6.1875 & 5.3952 & 4.5128 & 4.0313 & 3.4468 & 2.7111 & 2.5452 \\
\hline & & LTR & 6.2437 & 5.4428 & 4.5505 & 4.0635 & 3.4724 & 2.7308 & 2.5633 \\
\hline & & STR & 6.2731 & 5.4676 & 4.5701 & 4.0801 & 3.4856 & 2.7408 & 2.5724 \\
\hline & \multirow{3}{*}{0.1} & UTR & 6.5645 & 5.6605 & 4.6844 & 4.1628 & 3.5384 & 2.7674 & 2.5970 \\
\hline & & LTR & 6.6227 & 5.7092 & 4.7222 & 4.1946 & 3.5633 & 2.7859 & 2.6139 \\
\hline & & STR & 6.6532 & 5.7345 & 4.7418 & 4.2111 & 3.5760 & 2.7953 & 2.6224 \\
\hline & \multirow{3}{*}{0.2} & UTR & 7.0131 & 5.9630 & 4.8713 & 4.3025 & 3.6324 & 2.8222 & 2.6470 \\
\hline & & LTR & 7.0740 & 6.0129 & 4.9093 & 4.3341 & 3.6565 & 2.8395 & 2.6627 \\
\hline & & STR & 7.1058 & 6.0390 & 4.9291 & 4.3504 & 3.6689 & 2.8483 & 2.6707 \\
\hline
\end{tabular}


TABLE 3: Continued.

(b) Nonuniform porosity distribution

\begin{tabular}{|c|c|c|c|c|c|c|c|c|c|}
\hline \multirow{2}{*}{$\Delta T$} & \multirow{2}{*}{ Porosity volume fraction $\zeta$} & \multirow{2}{*}{ Thermal load type } & \multicolumn{7}{|c|}{$p$} \\
\hline & & & 0 & 0.1 & 0.3 & 0.5 & 1 & 5 & 10 \\
\hline \multirow{9}{*}{$120^{\circ} \mathrm{K}$} & \multirow{3}{*}{0} & UTR & 5.3070 & 4.5322 & 3.6640 & 3.1873 & 2.6072 & 1.8767 & 1.6932 \\
\hline & & LTR & 5.4484 & 4.6581 & 3.7733 & 3.2882 & 2.6996 & 1.9680 & 1.7859 \\
\hline & & STR & 5.5174 & 4.7190 & 3.8254 & 3.3357 & 2.7422 & 2.0091 & 1.8273 \\
\hline & \multirow{3}{*}{0.1} & UTR & 5.7317 & 4.8521 & 3.8977 & 3.3856 & 2.7723 & 2.0187 & 1.8367 \\
\hline & & LTR & 5.8736 & 4.9763 & 4.0030 & 3.4812 & 2.8577 & 2.1001 & 1.9185 \\
\hline & & STR & 5.9432 & 5.0366 & 4.0534 & 3.5265 & 2.8974 & 2.1370 & 1.9552 \\
\hline & \multirow{3}{*}{0.2} & UTR & 6.2204 & 5.2027 & 4.1405 & 3.5855 & 2.9324 & 2.1494 & 1.9670 \\
\hline & & LTR & 6.3646 & 5.3262 & 4.2426 & 3.6767 & 3.0118 & 2.2225 & 2.0398 \\
\hline & & STR & 6.4357 & 5.3867 & 4.2919 & 3.7201 & 3.0489 & 2.2558 & 2.0727 \\
\hline
\end{tabular}

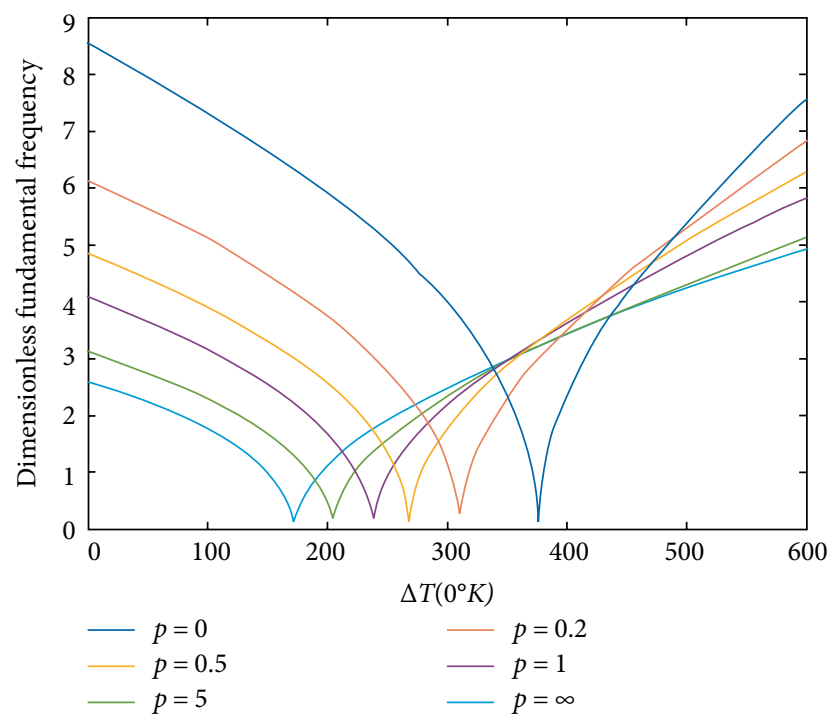

FIGURE 11: Effect of the temperature change $\Delta T$ on the dimensionless fundamental frequency of P-FGB with a uniform porosity distribution, subjected to a uniform temperature rise, for different values of $p$ and $L / h=20, \zeta=0.2$.

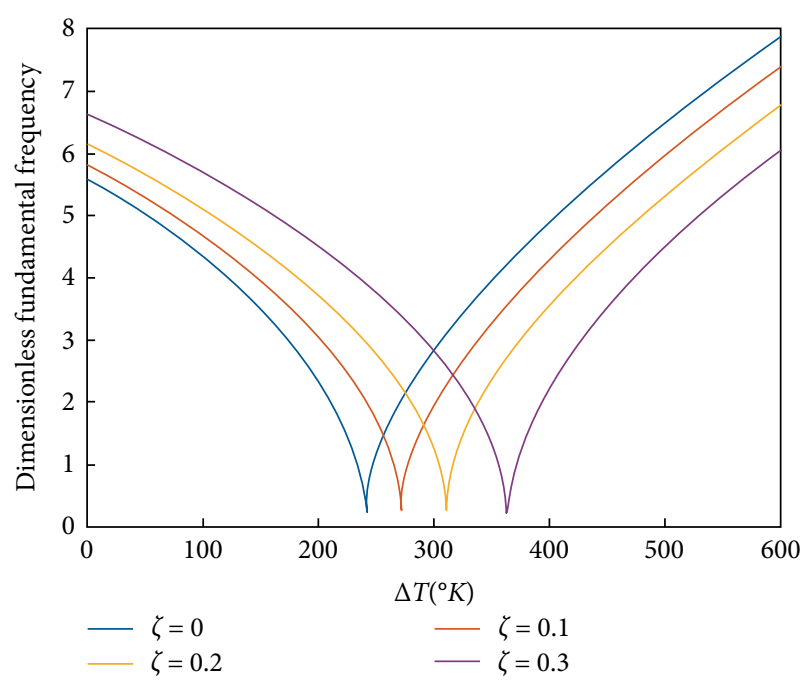

FIGURE 12: Effect of the porosity volume fraction $\zeta$ on the buckling temperature of P-FGB, with a uniform porosity distribution, subjected to a uniform temperature rise, for $p=0.2$ and $L / h=20$.

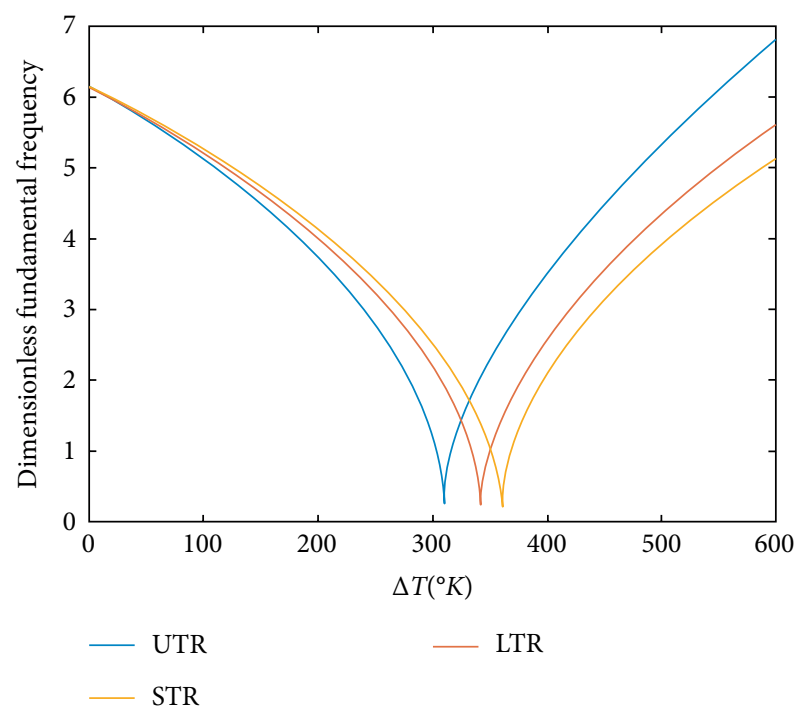

FIgURE 13: Effect of the thermal field shape on the buckling temperature and dimensionless fundamental frequency of P-FGB with a uniform porosity distribution, subjected to UTR, LTR, and STR, for $p=0.2, \zeta=0.2$, and $L / h=20$.

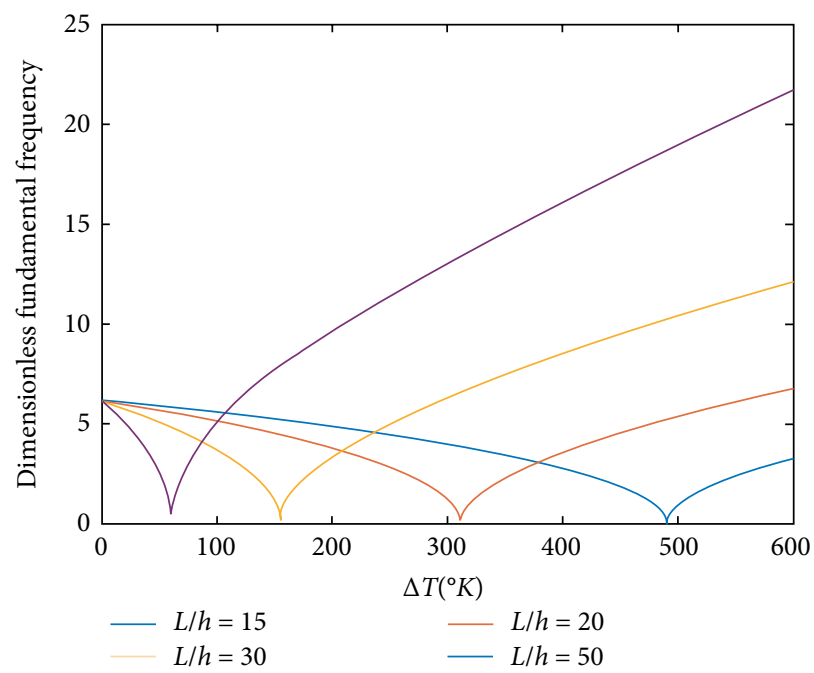

FIGURE 14: Effect the slenderness ratio of $L / h$ on the buckling temperature of P-FGB with a uniform porosity distribution, subjected to a uniform temperature rise, for $p=0.2, \zeta=0.2$. 


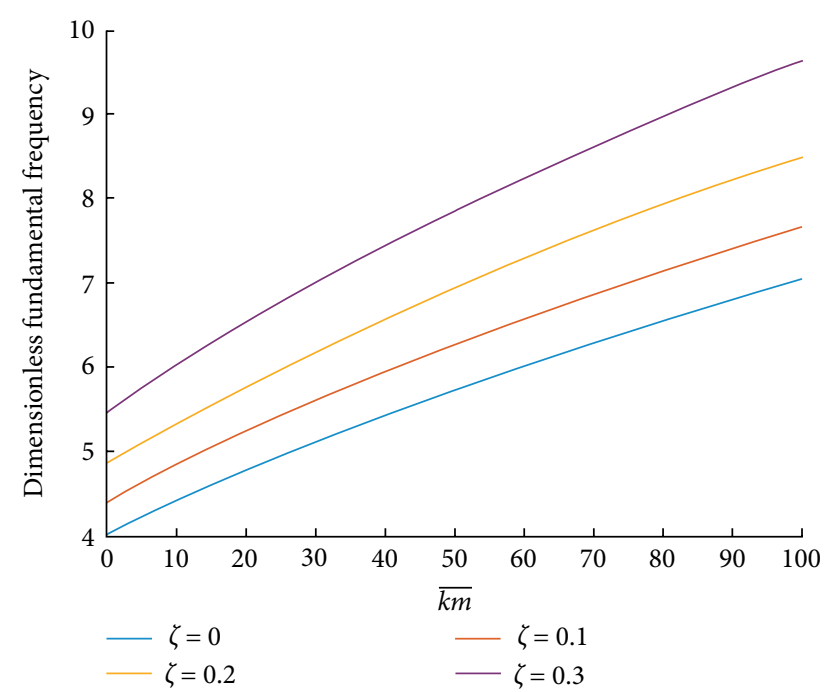

FIGURE 15: Effect of Winkler's parameter $\overline{k w}$ on the dimensionless fundamental frequency of P-FGB with uniform porosity distribution for different porosity parameters $\zeta$, subject to uniform temperature rise $\Delta T=120^{\circ} \mathrm{K}, L / h=20, p=0.2$, and $\overline{k p}=0$.

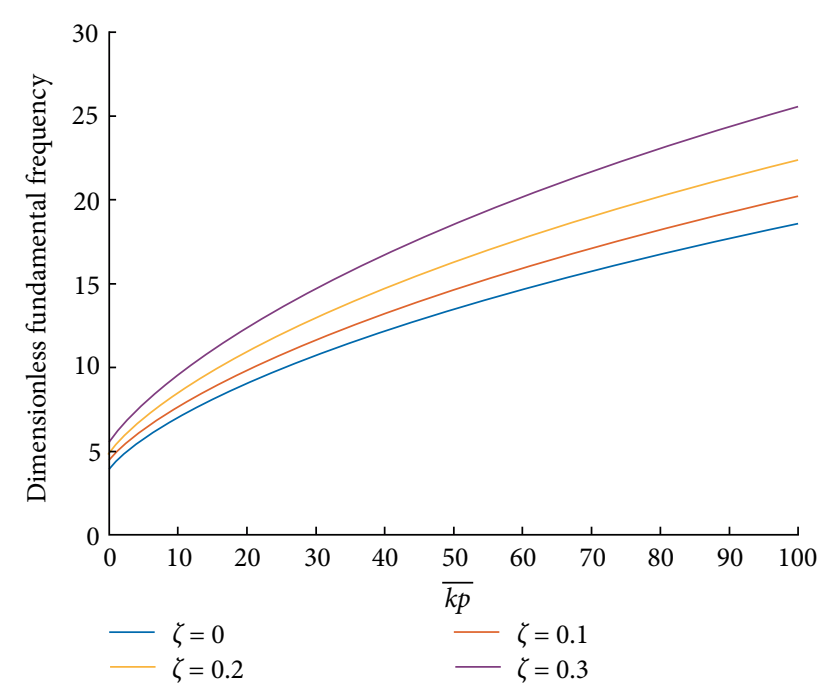

FIGURE 16: Effect of Pasternak's parameter $\overline{k p}$ on the dimensionless fundamental frequency of P-FGB with uniform porosity distribution for different porosity parameters $\zeta$, subject to uniform temperature rise $\Delta T=120^{\circ} \mathrm{K}, L / h=20, p=0.2$, and $\overline{k w}=0$.

including the porosity. The heat distribution along the beam height was examined in three cases: a uniform temperature rise (UTR), a linear temperature rise (LTR), and a sinusoidal temperature rise (STR). Two kinds of porosity distributions (uniform and nonuniform) were proposed. The Higher-order Shear Deformation Theory was extended to peruse the impact of several parameters on the linear bending vibration behavior of P-FGBs. The equations of motion have been derived using Hamilton's principle and the simply supported beam end conditions. The Navier-solution was used to solve the governing partial differential equations.

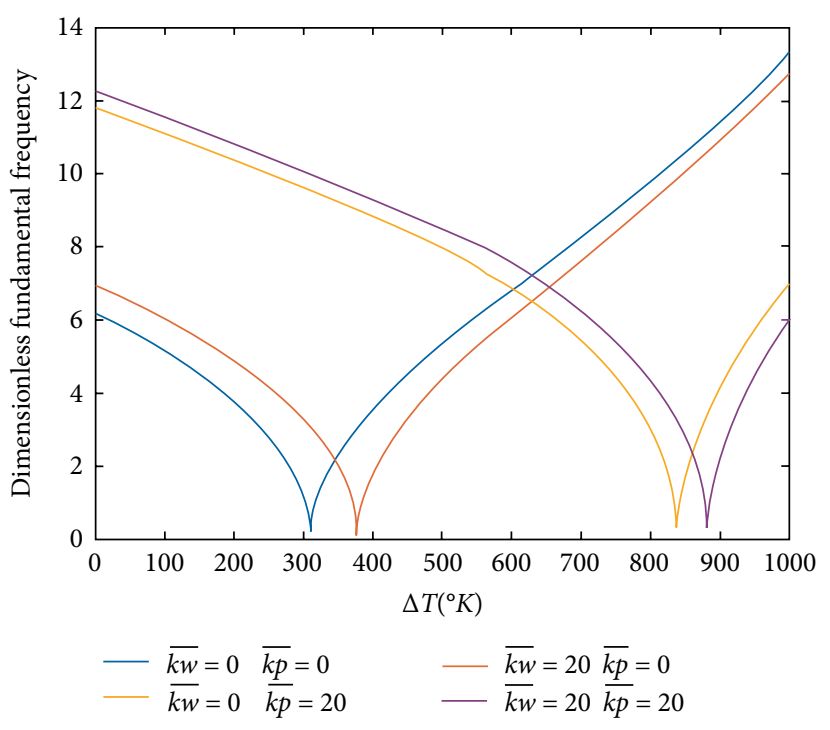

FIgURE 17: Effect of the combination of Winkler's and Pasternak's foundation parameters on the buckling temperature of P-FGB with a uniform porosity distribution subject to a uniform temperature rise for $\zeta=0.2, p=0.2$, and $L / h=20$.

The effects of several parameters such as the power-law index, the porosity index, the slenderness ratio of the beam, and the porosity distribution on the critical temperature of buckling and the natural frequencies of the P-FGB have been studied. The numerical results obtained show that:

(i) The increase in the material index $p$ leads to a decrease in the natural frequency.

(ii) The natural frequency tends to increase when the beam becomes shorter (or thicker).

(iii) The increase in the temperature causes a decrease in the natural frequency. This is due to the fact that increasing the temperature leads to a decrease in the rigidity of the material of the beam, while its mass remains constant.

(iv) The distribution of the temperature field has an enormous effect on the beam natural frequency and buckling temperature. The natural frequency and buckling temperature under the (STR) are greater than those under the (UTR) and the (LTR).

(v) For a uniform porosity distribution, the increase in the porosity causes first an increase in the natural frequency and buckling temperature. However, this trend is reversed for upper values of the gradient index $p$. This behavior is dependent on the gradient index $p$.

(vi) For a nonuniform porosity distribution, increasing the porosity causes an increase in the natural frequencies and buckling temperature for all values of the gradient index $p$.

(vii) The variation of the elastic foundation stiffness considerably affects the natural frequencies and buckling temperatures. The increase in both elastic foundation parameters increases the total stiffness of the system, 
and consequently the natural frequency and buckling temperature increase.

It is concluded that various factors, such as the material power-law index, the porosity parameter, the elastic foundation parameters, the porosity distribution, and the thermal field shape have a notable effect on the buckling temperatures and natural frequencies of porous FGBs. Therefore, these effects must be taken into account in the dynamic analysis of FG structures working in a thermal environment.

\section{Data Availability}

The data used to support the findings of this study are available from the corresponding author upon request.

\section{Conflicts of Interest}

The authors declare that there are no conflicts of interest regarding the publication of this paper.

\section{Acknowledgment}

This research was performed as part of the Modelling Structures and Mechanical Systems (M2SM) Mohammed V University in Rabat, Morocco. We would like to thank $\mathrm{Mr}$ Khalid EL Bikri responsible for the Laboratory (M2SM) and Mr Rhali Benamar Professor of Mechanical Engineering and Vibrations at the Mohammadia School of Engineering (EMI) of University Mohamed V who contributed to this research.

\section{References}

[1] M. Koizumi, "FGM activities in Japan," Composites Part B: Engineering, vol. 28, no. 1-2, pp. 1-4, 1997.

[2] B. V. Sankar, "An elasticity solution for functionally graded beams," Composites Science and Technology, vol. 61, no. 5, pp. 689-696, 2001.

[3] A. Chakraborty, S. Gopalakrishnan, and J. N. Reddy, "A new beam finite element for the analysis of functionally graded materials," International Journal of Mechanical Sciences, vol. 45, no. 3, pp. 519-539, 2003.

[4] A. Chakraborty and S. Gopalakrishnan, "A spectrally formulated finite element for wave propagation analysis in functionally graded beams," International Journal of Solids and Structures, vol. 40, no. 10, pp. 2421-2448, 2003.

[5] M. Aydogdu and V. Taskin, "Free vibration analysis of functionally graded beams with simply supported edges," Materials \& Design, vol. 28, no. 5, pp. 1651-1656, 2007.

[6] Z. Zhong and T. Yu, "Analytical solution of a cantilever functionally graded beam," Composites Science and Technology, vol. 67, no. 3-4, pp. 481-488, 2007.

[7] S. Kapuria, M. Bhattacharyya, and A. N. Kumar, "Bending and free vibration response of layered functionally graded beams: a theoretical model and its experimental validation," Composite Structures, vol. 82, no. 3, pp. 390-402, 2008.
[8] X. F. Li, "A unified approach for analyzing static and dynamic behaviors of functionally graded Timoshenko and EulerBernoulli beams," Journal of Sound and Vibration, vol. 318, no. 4-5, pp. 1210-1229, 2008.

[9] M. A. Benatta, I. Mechab, A. Tounsi, and E. A. Adda Bedia, "Static analysis of functionally graded short beams including warping and shear deformation effects," Computational Materials Science, vol. 44, no. 2, pp. 765-773, 2008.

[10] B. O. Sallai, A. Tounsi, I. Mechab, B. M. Bachir, M. Meradjah, and B. E. A. Adda, "A theoretical analysis of flexional bending of $\mathrm{Al} / \mathrm{Al}_{2} \mathrm{O}_{3}$ S-FGM thick beams," Computational Materials Science, vol. 44, no. 4, pp. 1344-1350, 2009.

[11] S. A. Sina, H. M. Navazi, and H. Haddadpour, "An analytical method for free vibration analysis of functionally graded beams," Materials \& Design, vol. 30, no. 3, pp. 741-747, 2009.

[12] M. Şimşek, "Static analysis of a functionally graded beam under a uniformly distributed load by ritz method," International Journal of Engineering and Applied Sciences, vol. 1, no. 3, pp. 1-11, 2009.

[13] S. M. R. Khalili, A. A. Jafari, and S. A. Eftekhari, "A mixed ritzDQ method for forced vibration of functionally graded beams carrying moving loads," Composite Structures, vol. 92, no. 10, pp. 2497-2511, 2010.

[14] T. Kocaturk, M. Şimşek, and Ş. D. Akbaş, "Large displacement static analysis of a cantilever timoshenko beam composed of functionally graded material," Science and Engineering of Composite Materials, vol. 18, no. 1-2, pp. 21-34, 2011.

[15] M. Şimşek and S. Cansız, "Dynamics of elastically connected double-functionally graded beam systems with different boundary conditions under action of a moving harmonic load," Composite Structures, vol. 94, no. 9, pp. 2861-2878, 2012.

[16] H. Su, J. R. Banerjee, and C. W. Cheung, "Dynamic stiffness formulation and free vibration analysis of functionally graded beams," Composite Structures, vol. 106, pp. 854-862, 2013.

[17] M. Rezaiee-Pajand and S. M. Hozhabrossadati, "Analytical and numerical method for free vibration of double-axially functionally graded beams," Composite Structures, vol. 152, pp. 488-498, 2016.

[18] M. H. Ghayesh, "Vibration analysis of shear-deformable AFG imperfect beams," Composite Structures, vol. 200, pp. 910-920, 2018.

[19] L. C. Trinh, T. P. Vo, H.-T. Thai, and T.-K. Nguyen, "An analytical method for the vibration and buckling of functionally graded beams under mechanical and thermal loads," Composites Part B: Engineering, vol. 100, pp. 152-163, 2016.

[20] A. El-Megharbel, "A theoretical analysis of FG beam under thermal loading," World Journal of Engineering and Technology, vol. 4, pp. 437-449, 2016.

[21] M. Şimşek, "Buckling of timoshenko beams composed of twodimensional functionally graded material (2D-FGM) having different boundary conditions," Composite Structures, vol. 149, pp. 304-314, 2016.

[22] R. Shahsiah, K. M. Shahsiah, and M. R. Eslami, "Thermal buckling of functionally graded beams," Iranian Journal of Mechanical Engineering, vol. 10, pp. 64-80, 2009.

[23] M. A. Eltaher, S. A. Emam, and F. F. Mahmoud, "Static and stability analysis of nonlocal functionally graded nanobeams," Composite Structures, vol. 96, pp. 82-88, 2013.

[24] X. Li, L. Li, H. Yujin, Z. Ding, and W. Deng, "Bending, buckling and vibration of axially functionally graded beams based on 
nonlocal strain gradient theory," Composite Structures, vol. 165, pp. 250-265, 2017.

[25] A. R. Davoodinik and G. H. Rahimi, "Thermal behavior analysis of the functionally graded timoshenko's beam," IUST International Journal of Engineering Science, vol. 19, pp. 105113, 2008.

[26] L. S. Ma and D. W. Lee, "A further discussion of nonlinear mechanical behavior for FGM beams under in-plane thermal loading," Composite Structures, vol. 93, no. 2, pp. 831-842, 2011.

[27] G. Giunta, S. Belouettar, and E. Carrera, "A thermal stress analysis of three-dimensional beams by refined one-dimensional models and strong form solutions," Applied Mechanics and Materials, vol. 828, pp. 139-171, 2016.

[28] A. Mahi, A. Tounsi, E. A. Adda Bedia, and I. Mechab, "An analytical method for temperature-dependent free vibration analysis of functionally graded beams with general boundary conditions," Composite Structures, vol. 92, no. 8, pp. 1877-1887, 2010.

[29] T. T. Thom and N. D. Kien, "Free vibration analysis of 2-D FGM beams in thermal environment based on a new thirdorder shear deformation theory," Vietnam Journal of Mechanics, vol. 40, no. 2, pp. 121-140, 2018.

[30] B. Akgöz and Ö. Civalek, "Thermo-mechanical buckling behavior of functionally graded micro beams embedded in elastic medium," International Journal of Engineering Science, vol. 85, pp. 90-104, 2014.

[31] D. Zhou, "A general solution to vibrations of beams on variable winkler elastic foundation," Computers \& Structures, vol. 47, no. 1, pp. 83-90, 1993.

[32] M. Eisenberger, "Vibration frequencies for beams on variable one- and two-parameter elastic foundations," Journal of Sound and Vibration, vol. 176, no. 5, pp. 577-584, 1994.

[33] Y. Sun, S.-R. Li, and R. C. Batra, "Thermal buckling and post-buckling of FGM timoshenko beams on nonlinear elastic foundation," Journal of Thermal Stresses, vol. 39, no. 1, pp. 11-26, 2016.

[34] S. D. Akbas, "Free vibration and bending of functionally graded beams resting on elastic foundation," Research on Engineering Structures and Materials, vol. 1, no. 1, pp. 25-37, 2015.

[35] S. E. Esfahani, Y. Kiani, and M. R. Eslami, "Non-linear thermal stability analysis of temperature dependent FGM beams supported on non-linear hardening elastic foundations," International Journal of Mechanical Sciences, vol. 69, pp. 10-20, 2013.

[36] H. Matsunaga, "Vibration and buckling of deep beam-columns on two parameter elastic foundations," Journal of Sound and Vibration, vol. 228, no. 2, pp. 359-376, 1999.

[37] C. N. Chen, "DQEM vibration analyses of non-prismatic beams resting on elastic foundations," Journal of Sound and Vibration, vol. 255, no. 5, pp. 989-999, 2002.

[38] P. Malekzadeh and G. Karami, "A mixed differential quadrature and finite element free vibration and buckling analysis of thick beams on two-parameter elastic foundations," Applied Mathematical Modelling, vol. 32, no. 7, pp. 1381-1394, 2008.

[39] J. Ying, C. F. Lü, and W. Q. Chen, “Two-dimensional elasticity solutions for functionally graded beams resting on elastic foundations," Composite Structures, vol. 84, no. 3, pp. 209-219, 2008.

[40] G. Karami, P. Malekzadeh, and S. A. A. Shahpari, "DQEM for free vibration of shear deformable non-uniform beams with general boundary conditions," Engineering Structures, vol. 25, pp. 1169-1178, 2003.

[41] S. C. Pradhan and T. Murmu, "Thermo-mechanical vibration of FGM sandwich beam under variable elastic foundations using differential quadrature method," Journal of Sound and Vibration, vol. 321, pp. 342-362, 2009.

[42] M. T. A. Robinson and S. Adali, "Buckling of non-uniform and axially functionally graded nonlocal timoshenko nanobeams on winkler-pasternak foundation," Composite Structures, vol. 206, pp. 95-103, 2018.

[43] M. Şimşek and J. N. Reddy, "A unified higher order beam theory for buckling of a functionally graded micro-beam embedded in elastic medium using modified couple stress theory," Composite Structures, vol. 101, pp. 47-58, 2013.

[44] K. A. Khor and Y. W. Gu, "Effects of residual stress on the performance of plasma sprayed functionally graded $\mathrm{ZrO}_{2} /$ NiCoCrAlY coatings," Materials Science and Engineering A, vol. 277, no. 1-2, pp. 64-76, 2000.

[45] S. Seifried, M. Winterer, and H. Hahn, "Nano-crystalline gradient films through chemical vapor synthesis," Scripta materialia, vol. 44, no. 8-9, pp. 2165-2168, 2001.

[46] Y. Watanabe, H. Eryu, and K. Matsuura, "Evaluation of three-dimensional orientation of $\mathrm{Al}_{3} \mathrm{Ti}$ platelet in $\mathrm{Al}$-based functionally graded materials fabricated by a centrifugal casting technique," Acta Materialia, vol. 49, no. 5, pp. 775-783, 2001.

[47] C. Song, Z. Xu, and J. Li, "Structure of in situ Al/Si functionally graded materials by electromagnetic separation method," Materials \& design, vol. 28, no. 3, pp. 1012-1015, 2007.

[48] X. Peng, M. Yan, and W. Shi, "A new approach for the preparation of functionally graded materials via slip casting in a gradient magnetic field," Scripta Materialia, vol. 56, no. 10, pp. 907-909, 2007.

[49] J. Zhu, Z. Yin, S. Lee, Z. Lai, and J. Jeon, "Fabrication of $\mathrm{ZrO}_{2}$ $\mathrm{NiCr}$ functionally graded material by powder metallurgy," Materials Chemistry and Physics, vol. 68, no. 1-3, pp. 130-135, 2001.

[50] N. Wattanasakulpong, B. G. Prusty, W. D. Kelly, and M. Hoffman, "Free vibration analysis of layered functionally graded beams with experimental validation," Materials \& Design, vol. 36, pp. 182-190, 2012.

[51] A. S. Rezaei and A. R. Saidi, "Application of carrera unified formulation to study the effect of porosity on natural frequencies of thick porous-cellular plates," Composites Part B: Engineering, vol. 91, pp. 361-370, 2016.

[52] L. Boutahar, K. El bikri, and R. Benamar, "A homogenization procedure for geometrically non-linear free vibration analysis of functionally graded annular plates with porosities, resting on elastic foundations," Ain Shams Engineering Journal, vol. 7, no. 1, pp. 313-333, 2016.

[53] N. Wattanasakulpong and V. Ungbhakorn, "Linear and nonlinear vibration analysis of elastically restrained ends FGM beams with porosities," Aerospace Science and Technology, vol. 32, no. 1, pp. 111-120, 2014.

[54] F. Ebrahimi and M. Mokhtari, "Transverse vibration analysis of rotating porous beam with functionally graded microstructure using the differential transform method," Journal of the Brazilian Society of Mechanical Sciences and Engineering, vol. 37, no. 4, pp. 1435-1444, 2015.

[55] N. Wattanasakulpong and A. Chaikittiratana, "Flexural vibration of imperfect functionally graded beams based on timoshenko 
beam theory: chebyshev collocation method," Meccanica, vol. 50, no. 5, pp. 1331-1342, 2015.

[56] F. Ebrahimi and M. Zia, "Large amplitude nonlinear vibration analysis of functionally graded Timoshenko beams with porosities," Acta Astronautica, vol. 116, pp. 117-125, 2015.

[57] H. Ait Atmane, A. Tounsi, and F. Bernard, "Effect of thickness stretching and porosity on mechanical response of a functionally graded beams resting on elastic foundations," International Journal of Mechanics and Materials in Design, vol. 13, no. 1, pp. 71-84, 2017.

[58] F. Ebrahimi and E. Salari, "Thermo-mechanical vibration analysis of nonlocal temperature-dependent FG nanobeams with various boundary conditions," Composites Part B: Engineering, vol. 78, pp. 272-290, 2015.

[59] F. Ebrahimi and A. Jafari, "Thermo-mechanical vibration analysis of temperature-dependent porous FG beams based on timoshenko beam theory," Structural Engineering and Mechanics, vol. 59, no. 2, pp. 343-371, 2016.

[60] F. Ebrahimi and A. Jafari, "A higher-order thermomechanical vibration analysis of temperature-dependent FGM beams with porosities," Journal of Engineering, vol. 2016, 20 pages, 2016.

[61] P. Zahedinejad, "Free vibration analysis of functionally graded beams resting on elastic foundation in thermal environment," International Journal of Structural Stability and Dynamics, vol. 16, no. 07, p. 1550029, 2016.

[62] R. Kadoli, K. Akhtar, and N. Ganesan, "Static analysis of functionally graded beams using higher order shear deformation theory," Applied Mathematical Modelling, vol. 32, no. 12, pp. 2509-2525, 2008.

[63] L. O. Larbi, A. Kaci, M. S. A. Houari, and A. Tounsi, "An efficient shear deformation beam theory based on neutral surface position for bending and free vibration of functionally graded beams," Mechanics Based Design of Structures and Machines, vol. 41, no. 4, pp. 421-433, 2013.

[64] T. P. Vo, H.-T. Thai, T.-K. Nguyen, and F. Inam, " Static and vibration analysis of functionally graded beams using refined shear deformation theory," Meccanica, vol. 49, no. 1, pp. 155$168,2014$.

[65] G. N. Praveen and J. N. Reddy, "Nonlinear transient thermoelastic analysis of functionally graded ceramic-metal plates," International Journal of Solids and Structures, vol. 35, no. 33, pp. 4457-4476, 1998.

[66] J. N. Reddy and C. D. Chin, "Thermomechanical analysis of functionally graded cylinders and plates," Journal of Thermal Stresses, vol. 21, no. 6, pp. 593-626, 1998.

[67] J. Yang and H. S. Shen, "Nonlinear bending analysis of shear deformable functionally graded plates subjected to thermomechanical loads under various boundary conditions," Composites Part B: Engineering, vol. 34, pp. 103-115, 2003.

[68] Y. S. Touloukian, "Thermophysical properties of high temperature solid materials. Volume 4. Oxides and their solutions and mixtures. Part I. Simple oxygen compounds and their mixtures," Defense Technical Information Center, 1966, https://apps.dtic.mil/docs/citations/AD0649951.

[69] S. Chi and Y. L. Chung, "Cracking in coating-substrate composites of multi-layered and sigmoid FGM coatings," Engineering Fracture Mechanics, vol. 70, no. 10, pp. 1227-1243, 2003.

[70] Y. Kiani and M. R. Eslami, "An exact solution for thermal buckling of annular FGM plates on an elastic medium," Composite Part B: Engineering, vol. 45, no. 1, pp. 101-110, 2013.
[71] K. S. Na and J. H. Kim, "Three-dimensional buckling analysis of functionally graded materials," Composite Part B: Engineering, vol. 35, no. 5, pp. 429-437, 2004.

[72] A. M. Zenkour, "A simple four-unknown refined theory for bending analysis of functionally graded plates," Applied Mathematical Modelling, vol. 37, no. 20-21, pp. 9041-9051, 2013.

[73] M. Şimşek, "Fundamental frequency analysis of functionnally graded beams by using higher-order beam theories," Nuclear Engineering and Design, vol. 240, no. 4, pp. 697-705, 2010. 


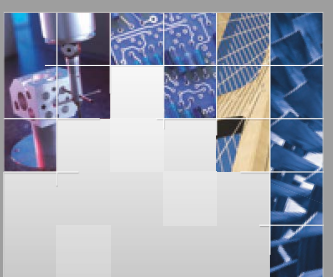

\section{Enfincering}
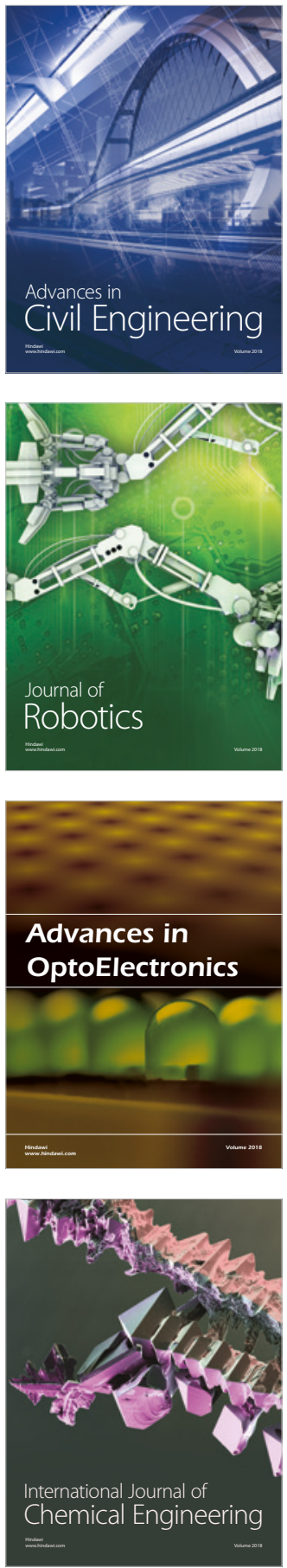

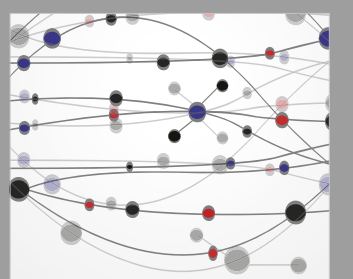

\section{Rotating \\ Machinery}

The Scientific World Journal

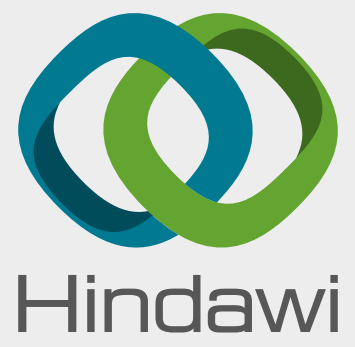

Submit your manuscripts at

www.hindawi.com
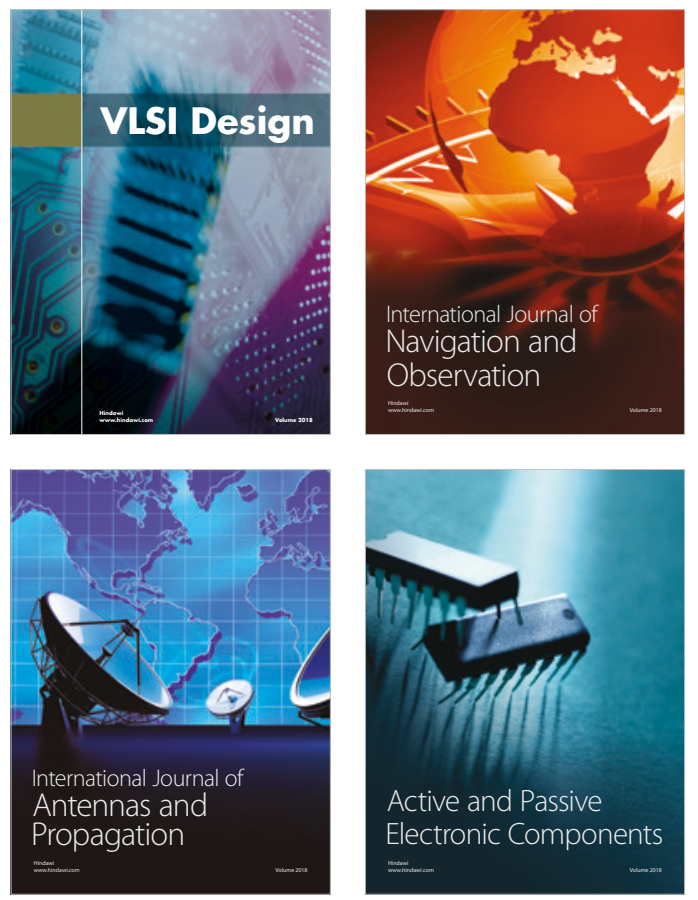
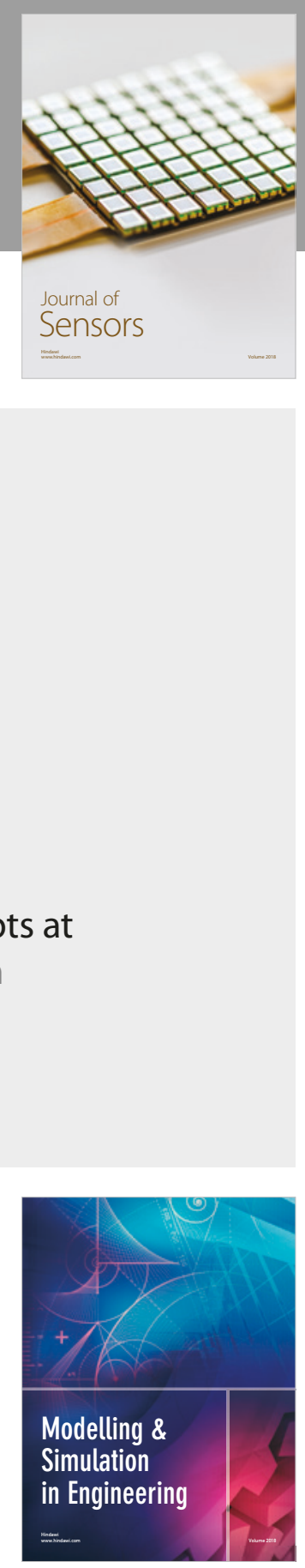

\section{Advances \\ Multimedia}
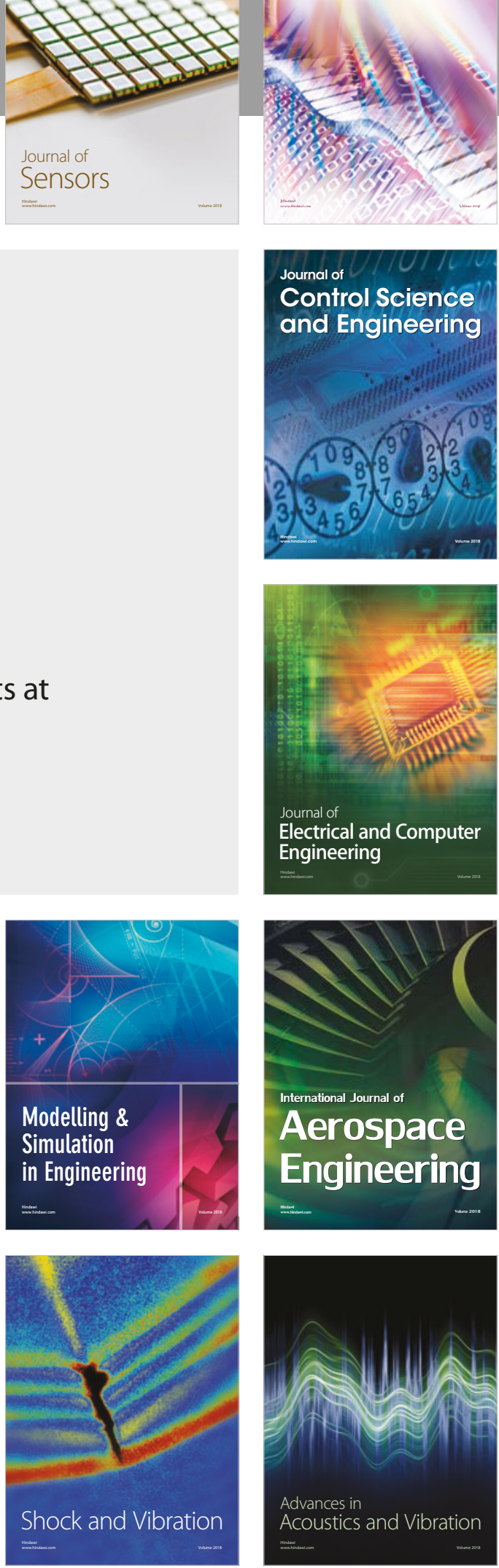